\title{
XII SIMPÓSIO DE INICIAÇÃO CIENTÍFICA DA FACULDADE DE MEDICINA DO ABC
}
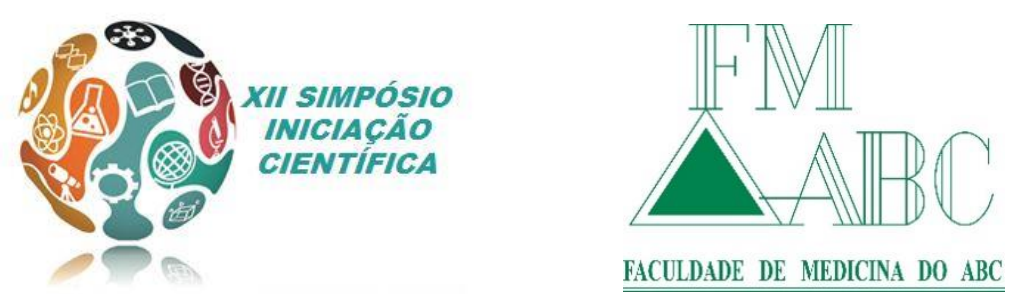

COMITÊ DE INICIAÇÃO CIENTÍFICA DA FMABC

Coordenadora: Profa. Dra. Denise Maria Christofolini

Vice-Coordenadora: Profa. Dra. Bianca Bianco

MEMBROS

Profa. Dra. Monica Akemi Sato

Prof. Dr. Fernando Luiz Affonso Fonseca

Prof. Dr. Ricardo Peres do Souto

DOI: http://dx.doi.org/10.7322/abcshs.v42i0.996 


\section{SÍNDROME METABÓLICA EM ADOLESCENTES: COMPARAÇÃO DA FREQUÊNCIA CONSIDERANDO TRÊS CRITÉRIOS PARA O DIAGNÓSTICO}

Adriana Cristina Viesti Domingues, Fabíola Isabel Suano de Souza, Giuliana Taralli, Roseli Oselka Saccardo Sarni

E-mail: adri.vdomingues@gmail.com

INTRODUÇÃO: O aumento da obesidade na faixa etária pediátrica relaciona-se com maior risco de doenças crônicas não transmissíveis. Há diversas propostas para classificação de Síndrome Metabólica (SM) nessa faixa etária, entretanto, não há consenso de qual seria a melhor em nosso meio. OBJETIVO: descrever a frequência de SM em pacientes, entre 10 a 16 anos de idade, do Ambulatório de Obesidade do Departamento de Pediatria da FMABC utilizando três critérios - American Heart Association (AHA), International Diabetes Federation (IDF) e Di Ferranti. MÉTODO: Realizou-se estudo transversal e retrospectivo com 133 crianças e adolescentes com sobrepeso/obesidade de causa exógena. Coletou-se dos prontuários dados da primeira consulta no ambulatório: idade; estadiamento puberal; pressão arterial sistêmica; peso e estatura, utilizados para classificação da condição nutricional por meio do cálculo do escore $\mathrm{z}$ do índice de massa corporal (ZIMC) e estatura/idade (ZE); circunferência abdominal e resultados do perfil lipídico (colesterol total, LDL-c, HDLc e triglicérides); glicemia e insulina. Análise estatística: teste Mann-Whitney, nível de significância 5\%. RESULTADO: Na população estudada 68 (51,1\%) eram do gênero masculino, a média de idade foi de 10,5 $\pm 2,6$ anos. Obesidade grave (ZIMC>+3) foi encontrada em $56(42,1 \%)$. Identificou-se SM pelo critério proposto pelo AHA em 11 $(8,3 \%)$, IDF $20(15,0 \%)$ e Di Ferranti 26 (19,5\%). As concentrações de insulina foram maiores no grupo classificado com SM pelo IDF $(14,6 \mathrm{uU} / \mathrm{mL}$ vs $8,4 \mathrm{uU} / \mathrm{mL} ; \mathrm{p}=0,019)$ e Di Ferranti $(16,8 \mathrm{uU} / \mathrm{mL}$ vs $8,4 \mathrm{uU} / \mathrm{mL} ; \mathrm{p}=0,010)$. Não houve associação entre a gravidade da obesidade e os diferentes critérios para classificação de SM. DISCUSSÃO: Critérios mais rigorosos para SM na proposta de Di Ferranti podem justificar a maior frequência encontrada e, mesmo assim, os níveis de insulina foram superiores as demais. Sabe-se que a resistência à insulina é o mecanismo central na associação entre obesidade, SM e diabetes melitos. Estudos longitudinais, que acompanhem crianças e adolescentes com obesidade e SM ao longo dos anos ajudarão a definir quais os melhores critérios a serem utilizados para essa classificação. CONCLUSÃO: O critério proposto por Di Ferranti, em comparação aos demais, detectou de forma mais frequente SM e relacionou-se com maiores concentrações de insulina em crianças e adolescentes com sobrepeso/obesidade.

Palavras-chave: síndrome metabólica, obesidade, intolerância à glicose

Apoio financeiro: PIBIC Institucional FMABC 


\title{
DETERMINAÇÃO DA CAPACIDADE ANTIOXIDANTE DE ESPECIES VEGETAIS DA REGIÃO AMAZÔNICA UTILIZANDO A FORMAÇÃO DOS COMPLEXOS DE FERRO(II) COM O LIGANTE 1,10- FENANTROLINA
}

\author{
Aline Freire Gouveia de Amorim, Cecilia Veronica Nunez, Horácio Dorigan Moya \\ E-mail: afreire310@hotmail.com
}

INTRODUÇÃO: Os compostos antioxidantes desempenham importante papel no sistema de defesa de um organismo, consumindo espécies reativas de oxigênio e de nitrogênio denominadas genericamente de radicais livres. Acredita-se que os componentes presentes nos alimentos que contribuam mais ativamente para essa proteção sejam as vitaminas, carotenos e polifenóis. Devido à presença desses compostos nos extratos vegetais, tem-se procurado desenvolver e utilizar métodos eficientes, rápidos, padronizados e com mecanismos de ação conhecidos para a avaliação da capacidade antioxidante total (CAT) dessas amostras. OBJETIVO: Desenvolver método analítico alternativo para quantificar a capacidade antioxidante de amostras de extratos vegetais de plantas amazônicas utilizando a formação dos complexos de ferro (II) com o ligante 1,10-fenantrolina. MÉTODO: O método consiste na substituição da solução padrão de ácido ascórbico (AA), o qual também reduz ferro (III) a ferrro(II) em solução contendo 1,10-fenantrolina, por um determinado volume de extrato aquoso da espécie vegetal. Utilizando a equação da reta da curva analítica com o AA pode-se calcular o valor de A511nm responsável pela CAT correspondente a uma solução de $1.0 \mathrm{mg} \mathrm{L}^{-1}$ de AA. Substituindo-se esse valor de $\mathrm{A}_{511 \mathrm{~nm}}$ na equação da reta obtida com a amostra pode-se encontrar a concentração desse extrato correspondente a mesma CAT da solução padrão de AA $1.0 \mathrm{mg} \mathrm{L}^{-1}$. Os valores obtidos de CAT foram comparados com o método do consumo do radical livre $\mathrm{DPPH}^{*}+$ (recomendado pela EMBRAPA) o qual usa solventes orgânicos (metanol e acetona) e com o teor total de polifenol (TTP). RESULTADOS E CONCLUSÃO: Observa-se boa correlação positiva $(r=0,848)$ entre os valores de CAT obtidos com o método proposto e com o método do radical $\mathrm{DPPH}^{\bullet}$, indicando que os complexos de ferro (II) com o ligante 1,10-fenantrolina podem ser usados para determinar a CAT de amostras vegetais. Além disso, os valores de CAT também mostram boa correlação quando comparados com o TTP $(r=0,775)$, sugerindo que os polifenóis devem ser os responsáveis pela CAT.

Palavras-chave: 1,10-fenantrolina, ferro, antioxidante, extratos vegetais 


\section{AVALIAÇÃO IN VIVO DO EFEITO HIPOGLICEMIANTE DO EXTRATO OBTIDO DA RAIZ DE PTERODON EMARGINATUS VOGEL}

Aline Scardoeli Faiola, Giuliana Petri, Jose Armando Junior, Bruno Machado Bertassoli, José Francisco Ramos dos Santos, David Feder

E-mail: aline.faiola@hotmail.com

INTRODUÇÃO: Em 2016, a International Diabetes Federation estimou que a prevalência de portadores de diabetes melitus (DM) no Brasil era de 10-12\%. Devido às altas taxas de morbidade e mortalidade do DM, o desenvolvimento de novas opções para seu tratamento se faz necessário, para ampliar fontes de recursos, disponibilidade e acessibilidade. OBJETIVO: Avaliar o efeito hipoglicemiante e potencial nefro e hepatotoxicidade do extrato da raiz de Pterodon emarginatus Vogel (sucupira-branca), planta utilizada popularmente no tratamento alternativo do DM. MÉTODO: 23 ratos machos Wistar (250-350g) foram tratados com aloxano $(120 \mathrm{mg} / \mathrm{kg}$ via subcutânea) para indução do DM. Somente ratos com glicemia superior a $200 \mathrm{mg} / \mathrm{dL}$ foram selecionados para o experimento. Os animais foram divididos em 3 grupos: DM-C, tratados com solução fisiológica; DM-T, tratados com doses constantes de $1.000 \mathrm{mg} / \mathrm{kg}$ do extrato; DM-TT, tratados com doses progressivas, em relação ao grupo DM-T, na taxa de $20 \%$ semanalmente. Os animais foram tratados diariamente por gavagem. Os grupos foram seguidos por 6 semanas, com realização de glicemia semanalmente por glicosímetro. Ao fim do experimento, foi feita punção da veia cava caudal para coleta de sangue para análise bioquímica (glicemia, AST, ALT, ureia, creatinina, colesterol e frações, triglicérides e proteínas totais e frações) e foram colhidas biópsias do fígado e rins. RESULTADOS: Os valores da glicemia medidos por glicosímetro apresentaram uma tendência à redução nos grupos tratados, mas não houve diferença estatística. Houve redução significativa da glicemia medida em laboratório nos animais do grupo DM-T em reação ao grupo controle. No grupo DM-TT, apesar de haver redução da glicemia em relação ao DM-C, esta não foi estatisticamente significativa. Não houve alteração no peso dos animais. A dosagem do colesterol total, HDL e não-HDL colesterol, triglicérides, creatinina, AST e ALT não apresentaram diferença estatística entre os diferentes grupos. CONCLUSÃO: Os resultados demonstram um efeito hipoglicemiante da raiz da sucupira-branca. A importância do resultado, o mecanismo de ação e as possibilidades terapêuticas do extrato requerem estudos subsequentes. Os resultados demonstraram que o extrato não altera os níveis de colesterol e triglicérides, nem as funções hepática e renal. O estudo anatomopatológico está em andamento.

Palavras-chave: Pterodon emarginatus Vogel, sucupira-branca, diabetes, glicemia

Apoio financeiro: PIBIC Institucional NEPAS 


\title{
EXPRESSÃO DA CATEPSINA X NO SANGUE DE PACIENTES PORTADORES DE TUMORES MALIGNOS DE PRÓSTATA E SUA RELAÇÃO COM PARÂMETROS CLINICO PATOLÓGICOS
}

\author{
Amanda de Almeida Soares Batista, Fernando Luiz Affonso Fonseca, Eloah Rabello Suarez \\ E-mail: amandadealmeidasb17@gmail.com
}

INTRODUÇÃO: A catepsina X (CTSX) é uma cisteína protease que é expressa em monócitos, macrófagos e células dendríticas. Esta enzima possui funções fisiológicas específicas, como a ativação do antígeno ligado a função linfocitária-1 (LFA-1), que facilita a migração de linfócitos para os tecidos, porém encontra-se super expressa em algumas neoplasias malignas, inclusive as de próstata. Sabe-se que a presença de LTs infiltrados nos tumores está diretamente associada com um melhor prognostico e maior sobrevida dos pacientes, mostrando a importância da CTSX contra o desenvolvimento tumoral. Logo, o aumento na infiltração dos linfócitos no microambiente tumoral, mediada pela CTSX, pode contribuir para a melhora no prognóstico dos pacientes. OBJETIVO: Analisar a expressão da CTSX no sangue total de 18 pacientes portadores de câncer de próstata por PCR em tempo real (qPCR), e correlacionar a expressão desta enzima com os parâmetros clínico-patológicos observados, comparando com um grupo controle formado por 20 indivíduos saudáveis. MÉTODO: O RNA do sangue total foi extraído, transcrito em cDNA e realizou-se o qPCR utilizando $S Y B R$ Green, $2 \mu \mathrm{L}$ de cDNA de cada amostra, e os primers sense e antisense para CTSX. As amostras foram amplificadas no termociclador, e a normalização da expressão dos genes alvo foi feita em relação à expressão de RPL13A à expressão de CTSX do grupo controle (2- $\Delta \Delta \mathrm{Ct})$. RESULTADOS: Os níveis de expressão de CTSX foram sete vezes mais altos pacientes sem recidiva $(p=0.027)$. Além disso, notou-se excelente correlação $(r=0.975)$ entre os níveis de expressão da CTSX e interleucina-2 (IL-2). CONCLUSÃO: A expressão da CTSX no sangue de pacientes portadores de tumores de próstata parece exercer um papel protetor contra o desenvolvimento tumoral, uma vez que apresenta níveis elevados em pacientes que não apresentaram recidiva. Ainda, a correlação entre CTSX e IL-2 indica que tal enzima pode estar envolvida com a mediação do processo inflamatório e estimulo de proliferação e ativação de linfócitos, que poderiam resultar em uma atividade antitumoral contra tumores de próstata.

Palavras-chave: catepsina X, câncer de próstata, linfócitos T 


\section{AVALIAÇÃO DE POLIMORFISMO DO GENE COL1A1 COMO FATOR DE RISCO RELACIONADO AO DESENVOLVIMENTO DE PROLAPSO GENITAL}

Beatriz Ferreira Timm, Émerson de Oliveira, Ricardo Peres do Souto

E-mail: timm.beatriz@gmail.com

INTRODUÇÃO: O prolapso genital é uma doença debilitante que não ameaça a vida, entretanto prejudica intensamente a qualidade de vida das pacientes. Essa condição ginecológica pode ocasionar incontinência urinária de esforço, dor vaginal e perineal, queixas sexuais e alterações da função intestinal, manifestando-se principalmente após os 60 anos. Portanto, a identificação precoce de mulheres com propensão ao prolapso genital é muito importante para adoção de medidas preventivas. Estudos revelam que o fator genético do prolapso genital estaria associado principalmente com genes relacionados à formação e remodelação de fibras de colágeno, visto que estas fibras representam componentes moleculares fundamentais para sustentação dos órgãos pélvicos. OBJETIVO: Avaliar o polimorfismo -1997G/T do gene de colágeno tipo I cadeia alfa-1 (COL1A1) como fator de risco relacionado ao desenvolvimento de prolapso genital em mulheres brasileiras. MÉTODO: Foi realizado estudo clínico transversal do tipo caso-controle incluindo 328 mulheres. Após avaliação ginecológica foram consideradas incluídas no grupo caso mulheres com prolapso em estádios III ou IV e no caso controle, em estádios I ou 0. Após extração de DNA de sangue das pacientes, a região promotora do gene COL1A1 foi amplificada por reação de polimerização em cadeia (PCR) e a genotipagem foi realizada pela análise dos produtos de digestão pela endonuclease de restrição BsaI em gel de agarose. RESULTADOS: Realizou-se a determinação do genótipo de 328 pacientes. Observouse que $162(49,4 \%)$ mulheres são homozigotas GG, 141 (43,0\%) mulheres são heterozigotas TG e $25(7,6 \%)$ mulheres são homozigotas TT. DISCUSSÃO: A frequência do alelo menos comum (T) foi maior que a relatada no banco de dados de polimorfismos de nucleotídeo único (dbSNP). CONCLUSÃO: Foi realizada a genotipagem do número planejado de pacientes. $O$ estudo da associação do polimorfismo -1997G/T do gene COL1A1 com o prolapso genital ainda não pode ser realizado, aguardando a quebra do duplo cego.

Palavras-chave: polimorfismo genético, prolapso genital, colágeno tipo I

Apoio financeiro: PIBIC CNPq, FAPESP, NEPAS 


\title{
EXPRESSÃO DA CICLOOXIGENASE-2 NA INDUÇÃO DE EXAUSTÃO DE LINFÓCITOS EM PACIENTES PORTADORES DE TUMORES MALIGNOS DE PRÓSTATA
}

\author{
Bianca Molinari Franco, Fernando Luiz Affonso Fonseca, Eloah Rabello Suarez \\ E-mail: biamolinari6@hotmail.com
}

INTRODUÇÃO: Os tumores superexpressam moléculas do checkpoint imunológico, como o ligante de morte programada-1 (PD-L1) que interage com seu respectivo receptor de morte programada-1 (PD-1), localizado nos linfócitos T (LT), tornando-os exaustos e, portanto, incapazes de bloquear o desenvolvimento tumoral. A ciclooxigenase-2 (COX-2) é uma enzima capaz de produzir mediadores próinflamatórios que promovem a ativação de vias de sinalização pró-tumorigênicas. $\mathrm{O}$ knockout de COX-2 em camundongos foi capaz de reduzir o crescimento tumoral e diminuir a expressão de PD-L1 em tumores de mama. Este fato sugere que a COX-2 poderia controlar a exaustão de LT em camundongos. OBJETIVO: Analisar a expressão de PD-1, IL-2, INFy e COX-2 por PCR em tempo real (qPCR) no sangue de 18 pacientes com câncer de próstata para análise do status de exaustão dos LT e correlacionar os dados obtidos com parâmetros clínico-laboratoriais. MÉTODO: O RNA foi extraído do sangue total dos pacientes e submetido à reação de transcrição reversa (RT-PCR). O qPCR foi realizado utilizando-se cDNA de cada amostra, SYBR Green Master Mix (2X), primers para cada gene (PD-1, IL-2, IFN $\gamma$ e COX2) e Rox (Thermo). As amostras foram amplificadas no termociclador Applied Biosystems ${ }^{\circledR}$ 7500 Real-Time PCR System (Life Technologies). RESULTADOS: Observamos uma redução significativa da expressão das citocinas pró-inflamatórias IL-2 e IFN $\gamma$ após a ressecção cirúrgica do tumor. Os níveis de PD-1 e COX2 pré e pós remoção do tumor foram mantidos. A expressão de PD-1 encontra-se elevada apenas nos tumores de próstata de alto risco de acordo com o Gleason da peça cirúrgica. Ainda, a expressão de PD-1 apresenta correlação moderada positiva $(\mathrm{r}=0,525)$ com a expressão de COX2 no período pós-operatório, indicando que ambos os genes são expressos de maneira coordenada. CONCLUSÃO: A relação linear $\left(R^{2}=0.920\right)$ entre COX2 e PD-1 estabelecida no período pós-operatório, corrobora com a hipótese de participação da COX2 no processo de exaustão dos LT.

Palavras-chave: exaustão, PD-1, COX-2, câncer de próstata

Apoio financeiro: PIBIC Institucional FMABC 


\section{RELAÇÃO DO PERFIL LIPÍDICO ATUAL COM O GANHO DE PESO DURANTE O PRIMEIRO ANO DE VIDA EM CRIANÇAS QUE NASCERAM COM MUITO BAIXO PESO}

Caroline da Freiria Castilho Reche, Denise Oliveira Schoeps, Fabíola Isabel Suano de Souza

E-mail: carol_reche@hotmail.com

INTRODUÇÃO: A prematuridade associa-se em longo prazo há maior risco para desenvolvimento de dislipidemias, HAS, obesidade e resistência insulínica. A recuperação nutricional ("catch-up growth") rápida nos primeiros anos de vida intensifica o risco para essas alterações. OBJETIVO: Descrever o perfil lipídico de crianças pré-púberes que nasceram com muito baixo peso ( $<1500$ gramas) e relacionar com o ganho de peso no primeiro ano de vida. MÉTODO: Por meio de estudo longitudinal, avaliou-se 44 crianças pré-púberes que nasceram com muito baixo peso com idade entre 4 e 10 anos. Coletou-se dados gerais (idade gestacional, peso ao nascer, tempo de internação), antropométricos (peso, estatura e circunferência craniana) aos 12 meses de vida e atual. Coletou-se também $10 \mathrm{~mL}$ de sangue após jejum de 12 horas para avaliação do perfil lipídico (colesterol total, LDL-c, HDL-c, não-HDL-colesterol e triglicérides). RESULTADO: A média de idade das crianças foi 7,0 $\pm 1,5$ anos, da idade gestacional 30,07 $\pm 4,92$ semanas e do peso ao nascer $1159 \pm 573 \mathrm{~g}$ ). Aos 12 meses de idade corrigida e na idade atual ZIMC>+2 foi observado em $1(2,2 \%)$ e $5(11,4 \%)$, respectivamente. Encontrou-se inadequação para colesterol total $20(45,5 \%)$, HDL-c em 3 (6,8\%), LDL-c em 10 (22,7\%), não HDL-c em 15 (34,1\%) e triglicérides em 17 (38,6\%) das crianças. Aquelas com IMC < p10 ao nascer apresentavam maiores valores de ZIMC aos 12 meses $(0,39 \pm 0,25$ vs $-0,63 \pm 0,21 ; p=0,004)$ e atual $(0,90 \pm 0,33$ vs $-0,40 \pm 0,20$; $\mathrm{p}=0,001)$, sem diferença nos parâmetros do perfil lipídico. Não houve diferença entre a variação do IMC no primeiro ano de vida das crianças com e sem dislipidemia 8,9 $\pm 0,6$ $\mathrm{kg} / \mathrm{m}^{2}$ vs $7,9 \pm 0,4 \mathrm{~kg} / \mathrm{m}^{2}$ ( $\left.\mathrm{p}=0,151\right)$. DISCUSSÃO: Os poucos trabalhos disponíveis sugerem que RNPT tem alteração no metabolismo lipídico, resultando em um perfil mais aterogênico. Na idade atual, 18,2\% apresentavam IMC elevado, sendo que 11,4\% eram obesos ou tinham obesidade considerada grave. Destes, $62,5 \%$ são mulheres. Este dado é preocupante, uma vez que a obesidade é a doença nutricional que mais cresce no mundo e é de difícil tratamento. CONCLUSÃO: Nesse estudo o menor IMC ao nascimento associou-se com maior aos 12 meses de vida e maior risco de obesidade aos 7 anos. Observou-se elevado percentual de dislipidemia na população estudada, entretanto, a variação do IMC no primeiro ano de vida não se associou com maior risco de dislipidemia.

Palavras-chave: prematuridade, dislipidemia, obesidade, pré-puberes 


\title{
REPERCUSSÃO PSICOSSOCIAL EM MULHERES VÍTIMAS DE VIOLÊNCIA POR PARCEIRO ÍNTIMO: IMPACTO NA PRODUTIVIDADE
}

\author{
Cinthia Emy Endo Amemiya, Carmen Silva Mollleis Galego Miziara
}

E-mail: cinthia.ea@gmail.com

INTRODUÇÃO: A violência contra a mulher causada por parceiro íntimo é considerada um grave problema de saúde pública mundial, pois, além da alta frequência, ela está relacionada a altas taxas de morbimortalidade. De acordo com a Organização Mundial da Saúde, esse tipo de violência ocorre em uma relação íntima, cujo parceiro causa dano físico, sexual ou psicológico, abrangendo atos de agressão física, coerção sexual, abuso psicológico e comportamentos controladores, resultando em transtornos psicossociais que repercutem negativamente na produtividade global das vítimas. OBJETIVO: Descrever a frequência de transtornos mentais presentes em mulheres que foram vítimas de violência por parceiro íntimo e o impacto desta violência na produtividade no trabalho e fora dele. MÉTODO: Estudo transversal por aplicação de questionários sociodemográfico, de qualidade de vida, de transtornos mentais não psicóticos e de impacto na produtividade em mulheres maiores de 18 anos de idade vítimas de violência por parceiro intimo. Foi constituído grupo controle. RESULTADOS: Foram avaliadas 34 mulheres do grupo de estudo, sendo $53 \%$ acima dos 25 anos e $47 \%$ entre 18 e 24 anos. O grupo controle foi composto por 30 mulheres, sendo $75,9 \%$ entre 18 a 24 anos e $24,1 \%$ acima dos 25 anos. A totalidade de mulheres do grupo de estudo sofreu mais de um tipo de agressão, sendo a violência emocional citada por todas elas, 18 (90\%) sofreram abuso físico e metade abuso sexual. Sessenta por cento das mulheres agredidas apresentaram transtornos mentais não psicóticos associado com o desemprego, enquanto que $26,6 \%$ do grupo controle apresentaram transtornos mentais não psicóticos. DISCUSSÃO: A violência contra a mulher, sobretudo quando o agressor é o parceiro, causa impacto negativo à saúde mental que compromete a produtividade laboral. CONCLUSÃO: Apoios psicológico e social são indispensáveis às mulheres vítimas de violência por parceiro íntimo objetivando minimizar o impacto psicossocial desta forma de crime contra a humanidade. A implantação de políticas públicas preventivas e educacionais para promover o empoderamento feminino e visar a quebra do paradigma cultural de que a mulher tem a obrigação de "servir" seu parceiro, facilitará o reconhecimento desta violência e a consequente denúncia.

Palavras-chave: violência contra a mulher, violência contra parceiro íntimo, violência doméstica 


\title{
PERCEPÇÃO DO PACIENTE ONCOLÓGICO E DE SEU ACOMPANHANTE SOBRE CUIDADOS PALIATIVOS
}

\author{
Clarisse Kaori Fujishige, Danielle Yumi Akaishi, Mariana Carvalho Gouveia, Marília Arrais \\ Garcia, Auro del Giglio, Daniel de Iracema Gomes Cubero
}

E-mail: clarisse.kf@gmail.com

INTRODUÇÃO: Os Cuidados paliativos são uma área de atuação da medicina que visa melhorar a qualidade de vida de pessoas portadoras de doenças incuráveis. Apesar de sua importância no tratamento integral de pacientes oncológicos, os Cuidados Paliativos ainda são pouco difundidos em nosso meio. OBJETIVO: Avaliar o entendimento de pacientes oncológicos e seus acompanhantes a cerca dos cuidados paliativos e elaborar cartilha educativa. MÉTODO: A primeira fase do projeto, aqui apresentada, consiste no diagnóstico do conhecimento da população a respeito dos cuidados paliativos para futura elaboração de cartilha educativa. Para isto elaborouse questionário com perguntas fechadas e abertas a serem aplicados por entrevistador no ambulatório de oncologia de um hospital universitário que atende ao Sistema Único de Saúde. RESULTADO: No período de Fevereiro a Abril de 2016 foram entrevistados 194 pessoas. A amostra era composta de 106 pacientes oncológicos e 87 acompanhantes, com idade mediana de 54,7 anos, representada em 59,8\% por mulheres e em sua maioria com nível de escolaridade fundamental até ensino médio (78,9\%). Para a pergunta "Você sabe o que são cuidados paliativos", apenas 13,9\% responderam "sim" e 8,8\% responderam "tenho uma leve ideia". Daqueles que responderam "sim" ou "tenho uma leve ideia", 6,8\% acreditavam que os cuidados paliativos serviam apenas para pacientes com câncer; $20,5 \%$ julgavam que os cuidados tinham como objetivo a cura da doença e 77,3\% acreditavam que aumentava o tempo de vida. DISCUSSÃO: Este trabalho traz informações sobre o grau de conhecimento da população estudada e as principais dúvidas a cerca do tema. CONCLUSÃO: Na população estudada há uma desinformação a cerca do tema, mesmo para aqueles que julgavam-se informados. Traz ainda os principais pontos de desinformação, que poderão ser utilizados em estratégias educacionais futuras.

Palavras-chave: cuidados paliativos, oncologia, conhecimento, pacientes ambulatoriais 


\section{TRIAGEM NEUROLÓGICA DE RECÉM-NASCIDOS PRÉ-TERMO COM SEPSE NEONATAL}

Daiane Cortez Quirino, Marina Ortega Golin

E-mail: daycortezfacu@gmail.com

INTRODUÇÃO: A sepse neonatal pode trazer repercussões prejudiciais ao neurodesenvolvimento, em especial de recém-nascidos pré-termo (RNPT). Por isso, a avaliação neurológica neonatal é essencial para identificar disfunções neurológicas e possibilitar intervenção precoce, com melhores resultados. No entanto, os protocolos existentes são extensos. Para viabilizar a aplicação, foi criada uma versão resumida do método Dubowitz com finalidade de triar RN (recém-nascidos) de risco que necessitem da avaliação completa. OBJETIVO: Avaliar e descrever o comportamento neurológico de RNPT com sepse neonatal, segundo versão resumida do Método Dubowitz. MÉTODO: A população do grupo estudo foi constituída por 50 RNPT com diagnóstico de sepse neonatal. E o grupo controle por 50 RNPT de baixo risco para disfunções neurológicas. As avaliações foram realizadas no Hospital Municipal de São Bernardo/SP. A versão resumida de Dubowitz é composta por 12 itens e são considerados itens de alerta as respostas não esperadas para a normalidade. Na presença de dois ou mais itens de alerta, o RN é considerado de risco. RESULTADOS: Sinais de alerta foram encontrados em $76 \%$ do grupo estudo e em $26 \%$ do controle. No grupo estudo, $46 \%$ foram classificados como risco e no controle apenas $4 \%$, com diferença estatisticamente significante $(p<0,001)$. DISCUSSÃO: As alterações neurológicas encontradas em RNPT com sepse vão de encontro com a literatura. Hentges et al. (2014) reforçam que a sepse neonatal em RNPT está associada, nos primeiros dois anos de vida, com atraso no neurodesenvolvimento. Segundo Cuestas et al. (2010) isso se deve à exposição a mediadores inflamatórios que causam efeitos deletérios ao sistema nervoso. CONCLUSÃO: A sepse neonatal em RNPT foi um fator determinante para a presença de itens de alerta e associada ao risco disfunções no neurodesenvolvimento. A versão resumida do Método Dubowitz mostrou-se ferramenta sensível para identificar as diferenças do comportamento neurológico nos RNPT estudados.

Palavras-chave: sepse neonatal, distúrbios do neurodesenvolvimento, neonato prétermo 


\title{
COMPARAÇÃO ENTRE TRIAGEM NEUROLÓGICA E VERSÃO COMPLETA DO MÉTODO DUBOWITZ DE RECÉM-NASCIDOS PRÉ- TERMO COM SEPSE NEONATAL
}

\author{
Daniel Hitoshi Matsubara, Marina Ortega Golin
}

E-mail: danielmtsu@gmail.com

INTRODUÇÃO: Em recém-nascidos pré-termo (RNPT), a sepse neonatal é um fator de risco de destaque para disfunções do neurodesenvolvimento. Isto devido à imaturidade do sistema imunológico, que desencadeia uma resposta inflamatória exacerbada, podendo causar danos ao encéfalo. A detecção precoce de lesões é a única estratégia para minimizar suas consequências negativas. O Método Dubowitz de avaliação neurológica neonatal possui altos índices de sensibilidade, porém muito extenso. Por isso foi estabelecida uma versão resumida com finalidade de triar RN (recém-nascidos) de risco que necessitem da avaliação completa. OBJETIVO: Comparar os resultados das versões completa e resumida (triagem) do Método Dubowitz em RNPT com sepse neonatal. MÉTODO: Participaram 100 RNPT, 50 do grupo estudo, que apresentaram sepse neonatal e 50 do controle, com baixo risco para disfunções neurológicas, do Hospital Municipal de São Bernardo do Campo. A versão completa do método é composta por 34 itens, e pontuações abaixo de 30,5 são consideradas atípicas e a resumida é composta por 12 itens e são considerados itens de alerta as respostas não esperadas para a normalidade. Na presença de dois ou mais itens de alerta, o RNPT é considerado de risco. RESULTADOS: Na versão completa, $84 \%$ do grupo estudo obtiveram pontuações atípicas e no grupo controle $26 \%$. Na versão resumida $46 \%$ do grupo estudo foram classificados como atípicos e no controle, $4 \%$. O índice de concordância de Kappa foi de $44 \%$ entre os métodos. No entanto, quanto maior a quantidade de itens de alerta, menores as pontuações totais $(p<0,001)$. DISCUSSÃO: A necessidade de um método de triagem neurológica neonatal eficiente e preciso se faz necessário na clínica atual. Isto, tendo em vista que, na rotina hospitalar, a aplicação da versão completa de Dubowitz a todos RNPT é inviável, pelo tempo necessário para sua aplicação (Domenico et al, 2012 ; Golin et al,2015). CONCLUSÃO: A versão resumida do Método Dubowitz não foi capaz de triar a maior parte dos RNPT com pontuações atípicas pela versão completa, mostrando sensibilidade apenas para os casos mais graves. Ambas as versões apontam que a sepse neonatal pode estar associada a disfunções neurológicas em RNPT.

Palavras-chave: sepse neonatal, distúrbios do neurodesenvolvimento, neonato prétermo 


\section{AVALIAÇÃO DO POLIMORFISMO DO GENE LISIL OXIDASE (LOX- L1) COMO FATOR DE RISCO PARA OCORRÊNCIA DE PROLAPSO DE ÓRGÃOS GENITAIS}

Danielle Yumi Akaishi, Raphael Federicci Haddad, Ramon Félix Martins Fernandes, Ricardo Peres do Souto, Cesar Eduardo Fernandes, Emerson de Oliveira

E-mail: danielle.akaishi@gmail.com

INTRODUÇÃO: O prolapso genital é uma condição ginecológica na qual ocorre deslocamento das vísceras pélvicas, que pode ocasionar incontinência urinária de esforço, dor vaginal e perineal, queixas sexuais, alterações intestinais bem como prejuízo à qualidade de vida e autoestima. Dessa forma, a identificação precoce de mulheres com propensão ao prolapso genital é muito importante para adoção de medidas preventivas. Estudo recente mostrou que duas variantes do gene da enzima lisil oxidase-like 1 (LOXL1), uma enzima envolvida no metabolismo da matriz extracelular, são mais frequentes em mulheres com prolapso. OBJETIVO: Avaliar aspectos clínicos como fatores de risco para o prolapso genital e verificar se o polimorfismo do gene LOXL1 pArg141 Leu (G>T) pode ser um fator de risco relacionado ao desenvolvimento de prolapso genital. MÉTODO: Foi realizado um estudo clínico transversal do tipo caso-controle incluindo 305 mulheres, sendo 119 casos (prolapso graus III ou IV) e 186 controles (graus I ou 0) recrutadas no ambulatório de Uroginecologia do CAISM-SBC. Após extração de DNA de sangue das pacientes, a região polimórfica do gene LOXL1 foi amplificada por Reação de Polimerização em Cadeia (PCR) e as variantes diferenciadas por após digestão pela enzima de restrição SmaI. As associações entre os grupos e variáveis clínicas foram avaliadas estatisticamente considerando significantes valores de p<0,05. RESULTADOS E DISCUSSÃO: Foram coletados os dados clínicos e antropométricos das 305 pacientes, encontrando associação positiva de prolapso genital em hipertensas, diabéticas e mulheres com maior paridade, e associação negativa do prolapso genital com incontinências urinárias e presença de história familiar. Em relação ao polimorfismo genético, não foi possível obter amplificação do gene LOXL1 usando dois pares distintos de primers descritos em artigos publicados, mesmo após ajustes em parâmetros do protocolo de PCR (temperatura e tempo de etapa de anelamento). CONCLUSÃO: Os fatores de risco para prolapso genital na população analisada não estão totalmente de acordo com os demais estudos realizados. O estudo genético ainda encontra-se em andamento e, portanto, não foi possível concluir se há alteração genômica entre as pacientes caso e controle em relação ao polimorfismo do gene LOXL1 pArg141Leu (G>T).

Palavras-chave: prolapso genital, polimorfismo, fatores de risco

Apoio financeiro: PIBIC Institucional NEPAS, FAPESP, NEPAS 


\section{RELAÇÃO ENTRE O ÍNDICE DE GINI, ÍNDICE DE DESENVOLVIMENTO HUMANO, PRODUTO INTERNO BRUTO E MORTALIDADE POR CÂNCER DE MAMA NO BRASIL. UM ESTUDO PROSPECTIVO}

Débora Terra Cardial, Fernando Adami, Francisco Winter dos Santos Figueiredo

E-mail: deboracardial@uol.com.br

INTRODUÇÃO: O câncer mais comum em mulheres é o de mama. A incidência e mortalidade podem estar relacionados ao desenvolvimento socioeconômico e redução das desigualdades. Há estudos que relacionam estes indicadores em cortes transversais, mas não do ponto de vista longitudinal. OBJETIVO: Avaliar se as mudanças nos indicadores de desigualdade de renda e desenvolvimento socioeconômico estão relacionadas a mudanças nos indicadores epidemiológicos do câncer de mama no Brasil (taxa de admissões hospitalares e mortalidade). MÉTODO: Estudo ecológico realizado a partir de dados secundários dos indicadores de desenvolvimento socioeconômico (IDH), de desigualdade econômica (índice de GINI) e da economia (PIB) no Brasil, obtidos do Programa das Nações Unidas para o Desenvolvimento e do Banco Mundial, de 2010 a 2014. Admissões hospitalares e mortalidade foram obtidos do DATASUS e as taxas para cada 100.000 mulheres foram padronizadas por idade. A variação anual dos indicadores foi analisada através do Annual Percent Change (APC) e sua variação média. A associação dos indicadores socioeconômicos com os do câncer de mama foi analisada por correlação e regressão linear ajustada por renda per capita. O nível de significância considerado foi de $5 \%$. O programa utilizado foi o Stata 11.0. RESULTADOS: No período, houve aumento dos indicadores epidemiológicos do câncer de mama, crescimento da economia brasileira e do desenvolvimento socioeconômico, acompanhado da redução da desigualdade econômica. Houve correlação negativa da mortalidade com o índice de GINI e mortalidade $(r=-0,88 ; p<0,044)$, e positiva com o IDH $(r=0,93 ; p<0,001)$. Também houve correlação positiva do IDH com a taxa de admissões hospitalares ( $\mathrm{r}=0,93$; $p=0,02)$. Nas análises ajustadas por renda média per capita, apenas o IDH está associado ao aumento da mortalidade. DISCUSSÃO: O desenvolvimento socioeconômico levou a um aumento da taxa de admissões hospitalares por câncer de mama, que pode ser explicado pelo maior número de diagnósticos, crescimento e envelhecimento populacional, além do aumento da escolaridade e renda da população brasileira. $\mathrm{O}$ aumento da mortalidade por câncer de mama ocorreu principalmente pelo aumento da incidência, e outras causas comuns a regiões em desenvolvimento. CONCLUSÃO: O aumento do desenvolvimento socioeconômico está associado ao aumento da mortalidade por câncer de mama no Brasil.

Palavras-chave: câncer de mama, índice de GINI, índice de desenvolvimento socioeconômico

Apoio financeiro: PIBIC Institucional FMABC 


\section{ABORDAGEM DA SEXUALIDADE FEMININA PELOS MÉDICOS GINECOLOGISTAS}

Fernanda Esteves Simões Ramos, Luciano de Melo Pompei

E-mail: fernandaesramos@gmail.com

INTRODUÇÃO: A sexualidade é um aspecto fundamental da saúde física e psicológica das mulheres. Pesquisas mostram que pacientes e médicos enfrentam barreiras à comunicação sobre sexualidade. Os ginecologistas devem estar bem preparados para resolver questões sobre sexualidade e condições do trato genital. OBJETIVO: Conhecer se o ginecologista avalia a função sexual feminina e o grau de dificuldade que apresenta ao fazer isso e se está preparado a oferecer tratamento às disfunções sexuais. Conhecer se este tema foi discutido durante a formação médica. MÉTODO: Ginecologistas brasileiros foram convidados por e-mail a responder um questionário online. Não houve contato físico com os sujeitos da pesquisa. Após concordar com o termo de consentimento livre e esclarecido (TCLE), o questionário é aberto com perguntas para avaliar seu conhecimento sobre abordagem da função e disfunções sexuais femininas e quanto isto foi discutido durante sua formação. RESULTADOS: 419 médicos ginecologistas responderam ao questionário desta pesquisa. $63 \%$ dos médicos informaram perguntar ativamente na anamnese se a paciente tem alguma queixa relativa à função sexual, independente do motivo da consulta. 410 dos 419 médicos se sentem apto a diagnosticar falha de lubrificação genital e 404 a tratar essa disfunção. Metade dos respondedores relata saber diagnosticar disfunção de orgasmo, e 127 desses se sentem aptos a tratá-la. Metade dos médicos relata não debater na graduação sobre função sexual e $20 \%$ relata debater sobre o tema frequentemente na residência. $O$ padrão se mantém semelhante no que se diz respeito as disfunções sexuais. DISCUSSÃO: Mais da metade dos ginecologistas relata abordar questões de sexualidade na anamnese sem serem solicitados por suas pacientes. Eles demonstram mais facilidade em tratar questões relativas aos órgãos sexuais do que disfunções de desejo ou orgásmica. CONCLUSÃO: Mesmo que parte dos ginecologistas se considera apta a diagnosticar disfunções sexuais, muitos ainda não se consideram preparada a tratá-las. Função e disfunções sexuais são mais debatidas na residência do que na graduação.

Palavras-chave: abordagem, sexualidade, disfunção sexual 


\section{CONCENTRAÇÕES DE VITAMINA D EM GESTANTES E SEUS RECÉM-NASCIDOS: RELAÇÃO COM O PESO AO NASCER E IDADE GESTACIONAL}

Fernanda Ramires Cafeo, Fabiola Isabel Suano de Souza

E-mail: fer.cafeo@gmail.com

INTRODUÇÃO: A Vitamina D (VITD) é um pró-hormônio envolvido no funcionamento do sistema imunológico, respiratório, endocrinológico, cardiovascular e metabolismo ósseo. Sabe-se que os RN prematuros apresentam maior chance de apresentarem deficiência $25(\mathrm{OH}) \mathrm{D} 3$ em relação aos que nasceram a termo. Sua deficiência pode se associar ao maior risco para doenças pulmonares, sepse e doenças ósseas. OBJETIVO: Descrever e avaliar, no momento do parto, as concentrações de $25(\mathrm{OH}) \mathrm{D}$ maternas e em cordão umbilical de RNPT (<32 semanas) e/ou de muito baixo peso (<1500 gramas). MÉTODO: Realizou-se estudo transversal e controlado que avaliou um grupo de RNPT $(n=65)$ que foi comparado com um de RNT $(n=105)$. Dados coletados, no momento do parto: condições da gestação (intercorrências, doenças associadas e uso de medicamentos); do recém-nascidos (idade gestacional, peso, comprimento e circunferência craniana). Das mães e recém-nascidos coletou-se $10 \mathrm{~mL}$ de sangue por venopunção periférica e do cordão umbilical, respectivamente, para dosagem das concentrações de 25(OH)D3, paratormônio, cálcio, fósforo e fosfatase alcalina. RESULTADOS: No grupo de RNPT a média do peso ao nascer e da idade gestacional foram, respectivamente, $1251 \pm 359$ gramas e 29,8 22,5 semanas. Destes $17(26,1 \%)$ e $12(18,5 \%)$ nasceram com extremo baixo peso e pequenos para idade gestacional, respectivamente. Houve diferença estatisticamente significante nas concentrações de $25(\mathrm{OH}) \mathrm{D} 3$ das gestantes entre o grupo pré-termo e termo $(21,4 \pm 10,6$ $\mathrm{ng} / \mathrm{mL}$ vs $26,7 \pm 9,9 \mathrm{ng} / \mathrm{mL} ; \mathrm{p}=0,002)$. O grupo de RNPT tiveram 3,7 vezes mais chance de apresentarem valores de 25(OH)D3 compatíveis com insuficiência $(<30 \mathrm{ng} / \mathrm{mL})$. Os níveis de 25(OH)D3 maternos correlacionaram-se com os do cordão umbilical no grupo de RNPT ( $r=0,555 ; \mathrm{p}<0,001)$ e RNT ( $\mathrm{r}=0,790 ; \mathrm{p}<0,001)$. Não se observou relação da VITD com o peso ao nascer em ambos os grupos. CONCLUSÃO: Gestantes que tiveram partos prematuros têm menores concentrações de vitamina $D$. As concentrações de mãe e recém-nascidos se correlacionam, de forma mais intensa no grupo de recém-nascidos à termo.

Palavras-chave: vitamina D, recém-nascidos, gestação, cordão umbilical

Apoio financeiro: FAPESP 


\section{CONCENTRAÇÕES PLASMÁTICAS E FREQUÊNCIA DE POLIMORFISMOS DO GENE DO RECEPTOR DA VITAMINA D EM GESTANTES: IMPACTO NOS PARÂMETROS ANTROPOMÉTRICOS DE RECÉM-NASCIDOS}

Fernando Alves Affonso Kaufman, Leticia Veríssimo Dutra, Fernanda Ramires Cafeo, Bianca Biano, Fabiola Isabel Suano de Souza

E-mail: fernandokaufman@hotmail.com

INTRODUÇÃO: As ações da vitamina D (VITD) são mediadas por receptores (receptores de vitamina D - VDR) que se localizam no núcleo celular. Alterações na conformação do gene VDR influenciam no risco para desenvolvimento de doenças ligadas ao metabolismo da VITD. A manutenção de concentrações adequadas de VITD durante a gestação é essencial para a saúde materna e fetal. A placenta expressa receptores de vitamina D e a 1,25-OH2-VITD3 no trofoblasto tem ação na implantação, síntese hormonal, resposta anti-inflamatória e antimicrobiana. OBJETIVO: Descrever as concentrações plasmáticas de $25(\mathrm{OH}) \mathrm{D} 3$ e a frequência de polimorfismos (SNP) do gene VDR (ApaI, Bsml, Fokl e Taql) em gestantes (37 a 42 semanas) e relacionar, com peso, comprimento e circunferência craniana do recém-nascido. MÉTODO: Por meio de estudo transversal, durante os meses de setembro/16 a março/17, incluiu-se 94 gestantes (37 a 42 semanas) durante o trabalho de parto no Hospital Municipal Universitário de São Bernardo do Campo. Coletou-se, por meio de questionário padronizado evolução da gestação (hábitos, doenças, uso de suplemento vitamínico e condição nutricional), condições do parto e da saúde do recém-nascido (peso, comprimento e circunferência craniana). Por venopunção periférica coletou-se da gestante e do cordão umbilical $15 \mathrm{~mL}$ de sangue para dosagem de 25(OH)D3, paratormonio e genotipagem do SNP (ApaI, Bsml, Fokl e Taql) do VDR. RESULTADOS: Na população estudada a frequência de deficiência de $25(\mathrm{OH}) \mathrm{D} 3<$ $20 \mathrm{ng} / \mathrm{mL}$ e hiperparatireoidismo foram de $28,7 \%$ e 12,2\%, respectivamente. A frequência de polimorfismo para Apal, Fokl, Bsml e Taql nas gestantes foram, 32,9\%; $21,9 \% ; 16,4 \%$ e $25,3 \%$; respectivamente. Não houve associação das concentrações de 25(OH)D3 das gestantes e do cordão umbilical com a presença dos SNP-VDR. Não houve diferença do peso, comprimento e circunferência craniana dos recém-nascidos em relação a presença de deficiência de 25(OH)D3 e SNP-VDR. CONCLUSÃO: Encontrou-se elevado percentual de deficiência de vitamina D e polimorfismos de receptor na população estudada, sem interferência nos indicadores antropométricos dos recém-nascidos avaliados.

Palavras-chave: vitamina $\mathrm{D}$, polimorfismo, receptor de vitamina $\mathrm{D}$, gestante, peso ao nascer

Apoio financeiro: PIBIC Institucional CEMEC 


\section{AVALIAÇÃO DA COMPOSIÇÃO CORPORAL EM PACIENTES SUBMETIDOS À CIRURGIA BARIÁTRICA ATRAVÉS DO USO DA BIOIMPEDÂNCIA}

Giovanna Bonetti Olivério, Laércio da Silva Paiva, Fernanda Benetti

E-mail: giovanna_bonetti@hotmail.com

INTRODUÇÃO: A cirurgia bariátrica está associada com o desenvolvimento de deficiências nutricionais que são previsíveis e tratadas baseadas na anatomia alterada cirurgicamente e mudanças dietéticas impostas. Tanto o sucesso da cirurgia quanto a incidência de deficiências nutricionais estão relacionadas a magnitude de perda de peso. OBJETIVO: Avaliar a composição corporal em pacientes submetidos a cirurgia bariátrica. MÉTODO: O projeto foi desenvolvido através da análise do exame de bioimpedância em pacientes obesos submetidos à cirurgia bariátrica, e a avaliação foi realizada antes da cirurgia e 3 meses. RESULTADOS: Após 3 meses de cirurgia, na técnica bypass houve redução no peso de 104,7 kg (IC 95\%: 95,2-122,3) para 87,8 kg (IC95\%: 76,3-99,2) gordura corporal de 52,4 kg (IC 95\%: 46,6-61) para 37,6 kg (IC95\%: $31,7-42,3)$, massa livre de gordura de 30,7 kg (IC95\%: 26,9-38,9) para 26,4 kg (IC95\%: 23,7-35,1). Na técnica sleve houve redução no peso de 107,4 kg (IC95\%: 99,3-124,8) para $86,5 \mathrm{~kg}$ (IC95\%: 77,2-104,4), gordura corporal de 50,7 kg (IC95\%: 46,3-59,6) para 37,7 kg (IC95\%: 34-49,6), massa livre de gordura de 29,3 kg (IC95\%: 26,9-35,9) para 26,3 kg $(23,3-31,7)$. Para ambas as técnicas houve diferenças estatisticamente significantes. DISCUSSÃO: Alguns estudos têm mostrado perda substancial de massa corporal magra e gordura corporal em pacientes submetidos à cirurgia bariátrica, relacionada à evolução clínica e nutricional desfavorável. Os resultados apresentados no presente estudo foram semelhantes àqueles observados em pesquisas que utilizam diferentes métodos de avaliação da composição corporal no seguimento de pacientes submetidos à cirurgia bariátrica, comprovando que os dois tipos de cirurgia bariátrica apresentaram diminuição significativa de peso, gordura corporal e massa livre de gordura, comparando antes e depois da mesma. CONCLUSÃO: Este estudo mostra, nos primeiros meses após a cirurgia bariátrica, houve uma diminuição nos componentes da composição corporal em pacientes submetidos a cirurgia bariátrica, sendo que ocorreu uma redução maior na técnica Bypass.

Palavras-chave: obesidade, fisioterapia, gastroplastia, qualidade de vida, cirurgia bariátrica, bioimpedância 


\title{
EFEITO DA ANGIOTENSINA 1-7 NA ÁREA PRÉOPTICA LATERAL NA REGULAÇÃO DA BEXIGA URINÁRIA DE RATAS WISTAR
}

\author{
Gustavo Bertollini Lamy, Monica Akemi Sato
}

E-mail: aeig92@hotmail.com

INTRODUÇÃO: Marcações por imuno-histoquímica evidenciaram a presença de receptores MAS para angiotensina-(1-7) na área préoptica lateral (APL). Entretanto, não se sabe se os receptores MAS para angiotensina-(1-7) presentes na APL teriam participação nos mecanismos de regulação da bexiga urinária. OBJETIVO: Verificar o efeito da injeção de angiotensina -(1-7) perifericamente e centralmente na APL sobre a pressão intravesical, pressão arterial, frequência cardíaca e fluxo sanguíneo renal de ratas Wistar. MÉTODO: Foram utilizadas 12 ratas Wistar $(\sim 240 \mathrm{~g})$. Seis ratas foram inicialmente submetidos à estereotaxia para implante de uma cânula-guia de aço inoxidável na APL sob anestesia com cetamina $(50 \mathrm{mg} / \mathrm{kg}$ i.p) e xilazina $(10 \mathrm{mg} / \mathrm{kg}$ i.m). Depois de uma semana da cirurgia esterotáxica, os animais foram anestesiados e mantidos com isoflurano $2 \%$ em $\mathrm{O}_{2} 100 \%$ e submetidos à canulação da artéria femoral, colocação de sonda miniaturizada de fluxometria Doppler ao redor da artéria renal esquerda para medida do fluxo sanguíneo renal e canulação da bexiga urinária para medida da pressão intravesical (PI). Nas ratas submetidas à administração in situ $(\mathrm{N}=6)$ de angiotensina-(1-7), não foi realizada a estereotaxia. Após a medida basal da PI, pressão arterial e fluxo sanguíneo renal por $15 \mathrm{~min}$, foi realizada a microinjeção de angiotensina (1-7) $(5 \mathrm{nmol} / \mathrm{uL})$ ou salina $(1 \mathrm{uL})$ na APL ou a administração in situ de angiotensina (1-7) $(10 \mathrm{ng} / 0,1 \mathrm{~mL})$ ou salina $(0,1 \mathrm{~mL})$ e as variáveis foram mensuradas durante mais $60 \mathrm{~min}$. RESULTADO: Observou-se aumento da PI após a injeção de angiotensina (1-7) na APL (187,5 $\pm 37,2 \%$ vs. $-2,1 \pm 1,9 \%$ salina), assim como um aumento da PI $(147,4 \pm 18,9 \%$ vs. $3,2 \pm 2,8 \%$ salina) após administração in situ de angiotensina (17). Não foram observadas alterações significantes dos parâmetros cardiovasculares e condutância renal. CONCLUSÃO: Os resultados obtidos sugerem que a APL seja parte importante do circuito que modula a atividade da bexiga urinária mediado pela angiotensina (1-7), bem como indicam também que angiotensina-(1-7) exerce ação diretamente na bexiga urinária.

Palavras-chave: área préoptica lateral, bexiga urinária, pressão intravesical, angiotensina (1-7) 


\section{ASSOCIAÇÃO DE VARIANTES DOS GENES COL9A2 E COL9A3 COM A DEGENERAÇÃO DISCAL}

Igor Luiz Argani, Carla Peluso, Aline Amaro, Matheus Delfino, Bianca Bianco, Luciano Miller

\section{E-mail: igorlargani@gmail.com}

INTRODUÇÃO: Estudos em camundongos e humanos mostraram que mutações no gene do colágeno tipo IX e na agrecan podem causar degeneração discal (DD) e hérnia de disco, alterando as propriedades do colágeno do disco intervertebral, contribuindo para o desenvolvimento da doença. OBJETIVO: Identificar as variantes rs137853213 do gene COL9A2/TG>CA e rs61734651/C>T do gene COL9A3 em pacientes com DD e no grupo controle. MÉTODO: Foram selecionados 107 indivíduos saudáveis (grupo controle, 32,0 044,3 anos, $78,5 \%$ mulheres e $21,5 \%$ homens) e 116 com DD (40,0 05,7 anos, sendo $51,7 \%$ mulheres e $48,3 \%$ homens). A genotipagem foi realizada pelo método TaqMan por PCR em tempo real. A distribuição de genótipos e a frequência de alelos foram calculadas. RESULTADOS: Para o polimorfismo rs61734651 do gene COL9A3 foi encontrado somente o genótipo homozigoto selvagem nos dois grupos estudados. Considerando o polimorfismo rs137853213 do gene COL9A2, a frequência dos genótipos estava em equilíbrio de Hardy-Weinberg para os grupos caso e controle e houve associação entre o polimorfismo e a DD (alelo selvagem TG, $p=0,026$ ), onde os indivíduos homozigotos selvagens (TG/TG) apresentaram maior chance de desenvolver a doença em relação aos heterozigotos. DISCUSSÃO: Os dois polimorfismos estudados são missense. No polimorfismo COL9A2 rs137853213 ocorre a substituição dos nucleotídeos TG por CA na posição 14790 do gene e, consequentemente, a troca do aminoácido glutamina por triptofano na posição 326 da proteína. No polimorfismo rs61734651 do gene COL9A3, há uma substituição dos nucleotídeos $\mathrm{C}$ por $\mathrm{T}$ na posição 310 do gene e, consequentemente, a troca do aminoácido arginina por triptofano na posição 103 da proteína. A troca de aminoácidos na proteína leva a malformação de heterotrímero de colágeno tipo II, IX e XI e pode tornar o disco intervertebral mais frágil. O resultado na frequência dos genótipos varia conforme os estudos e pode ser resultado, principalmente, da diferença na composição étnica e também na seleção dos grupos de estudo. CONCLUSÃO: Este é o primeiro estudo na população brasileira considerando os polimorfismos rs137853213 do gene COL9A2 e rs61734651 do gene COL9A3 em pacientes com DD. O polimorfismo COL9A2 rs137853213 foi positivamente associado a DD, especialmente os indivíduos com genótipo homozigoto selvagem (TG/TG).

Palavras-chave: degeneração discal, polimorfismos genéticos, gene COL9A2, gene COL9A3

Apoio financeiro: PIBIC Institucional NEPAS 


\section{ANÁLISE MULTIFATORIAL PARA A EXTRAÇÃO DE COMPOSTOS FENÓLICOS DE FOLHAS SECAS DE MYRCIA SPECTABILIS DC}

Jaqueline Oliveira dos Santos, Mara Angelina Galvão Magenta, Robson Miranda da Gama, José Armando Júnior

E-mail: jak_oliveira10@hotmail.com

INTRODUÇÃO: Espécies da família Myrtaceae são usadas em distúrbios gastrointestinais, estados hemorrágicos e doenças infecciosas e sua ação podem estar associadas à sua adstringência, provavelmente devido a presença de substâncias fenólicas. A espécie Myrcia spectabilis DC é representada por árvores com ampla distribuição na Mata Atlântica. O uso de métodos estatísticos como o delineamento fatorial (DoE) permite avaliar a relação entre vários fatores que influenciam a extração de substâncias ativas de plantas para obter suas melhores condições extrativas com um maior teor de compostos ativos para uso em medicamentos. OBJETIVO: Determinar as melhores formas de obtenção de extratos com maior concentração de taninos, fenóis, flavonoides e a atividade antioxidante das folhas secas desta espécie. MÉTODO: Neste estudo foram avaliados cinco fatores considerados importantes no processo de obtenção de extratos em dois diferentes níveis: razão droga/solvente (5:100 e 10:100) solvente extrator (etanol 70\% e absoluto), tempo de extração (6 e 24h), $\mathrm{pH}$ do líquido extrator (3 e 12) e agitação (com ou sem). Os experimentos foram realizados de acordo com o DoE usando matriz $2^{5}$ do software Minitab $\AA$, resultando em 32 ensaios. Foram obtidos os teores de taninos e fenóis por precipitação; o teor de flavonoides por calorimetria e a atividade antioxidante pelo método de DPPH. RESULTADOS E DISCUSSÃO: Os resultados mostraram que a melhor condição extrativa para fenóis totais e flavonoides são: etanol absoluto, razão droga/solvente $5 \%$; $\mathrm{pH} 3,0$; com agitação por 24 horas. Já para a atividade antioxidante extrato obtido em etanol 70\%; razão droga/solvente 5\%; pH 3,0; sem agitação por 24 horas é a melhor condição. Entretanto, para taninos totais o único fator que favorece sua extração é a razão droga/solvente 5\%. CONCLUSÃO: De acordo com os resultados nas condições experimentais aplicadas conclui-se que o DoE maximiza a quantidade de informações advindas dos experimentos realizados.

Palavras-chave: myrtaceae, fenóis, atividade antioxidante

Apoio financeiro: PIBIC Institucional NEPAS 


\section{TENDÊNCIA TEMPORAL DA MORTALIDADE POR AVC SEGUNDO SEXO EM ADULTOS JOVENS NAS REGIÕES BRASILEIRAS: ESTUDO DESCRITIVO ENTRE 1997 E 2012}

Jean Henri Maselli Schoueri, Laércio da Silva Paiva, Luiz Vinicius de Alcântara Sousa, Rodrigo Daminello Raimundo, Fernando Adami

E-mail: jean.schoueri@gmail.com

INTRODUÇÃO: O Acidente Vascular Cerebral (AVC) apresenta grande significância em adultos jovens, pois há sequela socioeconômica em um período de grande produtividade dos indivíduos. Há divergência na literatura a respeito da magnitude da mortalidade por AVC em indivíduos de 15 a 49 anos entre os sexos e há dúvida acerca da relação das condições socioeconômicas das regiões do Brasil com o risco de AVC. OBJETIVO: Analisar a tendência temporal da mortalidade por AVC segundo sexo em indivíduos de 15 a 49 anos, nas regiões do Brasil, entre 1997 a 2012. MÉTODO: Estudo descritivo de base populacional com dados provenientes do DATASUS. O AVC foi definido de acordo com a CID-10. Após calculada a mortalidade bruta, padronizou-se a taxa por idade pelo método direto segundo população da OMS. As frequências relativa e absoluta foram utilizadas para descrever a mortalidade. Aplicou-se regressão linear para comparar tendências temporais, estimando-se a inclinação $(\beta)$, probabilidade $(p)$ e capacidade preditiva do modelo $\left(\mathrm{r}^{2}\right)$. A variação percentual (PC) e variação percentual anual (APC) são as duas medidas de tendência da análise. O nível de confiança adotado foi de 95\%. RESULTADOS: No Brasil, entre 1997 e 2012, ocorreram 62.751 mortes em homens e 62.115 mortes em mulheres na faixa etária estudada. Há queda progressiva da taxa de mortalidade padronizada por idade em ambos os sexos no país e em suas regiões, sendo pouco superior nos homens. $\mathrm{O}$ Sudeste apresentou maior redução de mortes por AVC em homens e mulheres e a região Norte apresentou menor redução do risco. Todos os resultados foram significativos. DISCUSSÃO: A queda nas taxas de mortalidade pode ser devido a maiores cuidados relacionados a fatores de risco modificáveis. De modo geral, houve melhora no reconhecimento e tratamento do quadro nas últimas duas décadas. Ainda, a literatura aponta para possível associação entre status socioeconômico e risco de AVC. Ao dar enfoque à prevenção da doença, evita-se o evento e suas complicações relacionadas à recuperação mais lenta, piores resultados funcionais, aumento da mortalidade e altos custos hospitalares. CONCLUSÃO: A mortalidade por AVC tem diminuído no Brasil e em todas as regiões do país tanto em homens quanto em mulheres, sendo ligeiramente superior nos homens. A região Sudeste apresentou maiores quedas e a região Norte, as menores em ambos os sexos.

Palavras-chave: acidente vascular cerebral, epidemiologia, mortalidade, tendência temporal

Apoio financeiro: PIBIC CNPq 


\section{ESTUDO DOS EFEITOS POTENCIALIZADORES DE BEBIDAS ENERGÉTICAS CAFEINADAS E ADOÇADAS SOBRE $O$ COMPONENTE DO CRAVING ASSOCIADO AO CONSUMO DE ÁLCOOL, EM RATOS}

Juliana Jorge Romano, Giuliana Petri, José Francisco Ramos dos Santos, Cristina de Zotti Nassis

E-mail: julianajromano@uol.com.br

INTRODUÇÃO: O consumo de etanol associado a bebidas energéticas é uma tendência entre os jovens. Componentes energéticos mascaram os efeitos do etanol, levando à sua maior ingestão, no entanto, não existem estudos experimentais sobre possíveis efeitos amplificadores de energéticos sobre o craving do etanol. OBJETIVO: Investigar os efeitos da administração concomitante de uma bebida energética (Red Bull@) sobre o craving por etanol. MÉTODO: 35 ratos Wistar divididos em 5 grupos: grupo não condicionado (G0) e grupos condicionados, recebendo: etanol (G2), energético (G3), associação (G4) e solução salina (G1). O condicionamento consistiu em 4 dias de tratamento e pareamento entre os braços de um labirinto em t elevado. No teste, cada rato pôde explorar livremente todo o aparelho por 5 minutos. A percentagem de entradas nos braços abertos foi obtida para cada rato. Médias e SEMs foram calculados para cada grupo. Os dados foram submetidos a uma análise de variância de dois fatores (two-way ANOVA), tendo como fator independente o tratamento e as tentativas de fuga dos braços abertos como fator dependente. G1 foi comparado aos outros grupos por ANOVA bidirecional seguida de teste de Fisher $(p<0,05)$, da mesma forma, comparou-se G0 e G1. RESULTADOS: percentagens de entradas nos braços abertos (média +/- desvio padrão): G0: 56,4 +/- 14,8; G1: 22,18 +/- 8,85*; G2: 33,6 +/-

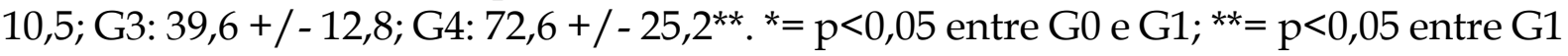
e G4. Após os 4 dias de condicionamento, os grupos tratados com álcool e energético isolados não se mostraram estatisticamente diferentes do grupo controle, enquanto que o grupo que recebeu a mistura apresentou um número de entradas no braço aberto maior do que o do controle. O grupo controle mostrou-se estatisticamente diferente do grupo não condicionado. DISCUSSÃO: Resultados indicaram que o craving associado ao etanol e à bebida energética não foram desencadeados no período de 4 dias, porém, no mesmo período os animais desenvolveram o craving pela mistura. A significância estatística entre os grupos 0 e 1 mostra que o condicionamento foi obtido, validando o protocolo experimental. CONCLUSÃO: Após condicionamento, a bebida energética com etanol foi capaz de induzir o craving, permitindo a inferência de que o uso concomitante dessas bebidas amplifica os riscos de se desenvolver abuso, compulsão e dependência.

Palavras-chave: etanol, craving, bebidas energéticas, ratos

Apoio financeiro: PIBIC Institucional NEPAS 


\section{ASSOCIAÇÃO ENTRE INDICADORES DE ADIPOSIDADE E MATURAÇÃO SEXUAL EM CRIANÇAS E ADOLESCENTES BRASILEIROS}

Livia Akemi Ramos Takahashi, Fernando Adami

E-mail: liviaart@hotmail.com

INTRODUÇÃO: Durante a maturação sexual indicadores de adiposidade começam a aumentar, o que permite questionar se alterações na maturação sexual influenciam no ganho de adiposidade que acontece com a idade. OBJETIVO: Analisar se há variação dos indicadores de adiposidade com a idade segundo os status de maturação sexual em crianças e adolescentes brasileiros. MÉTODO: Estudo transversal realizado com banco de dados coletado na cidade de Florianópolis (SC - Brasil), com meninos e meninas de 7 a 14 anos de idade. Maturação sexual foi avaliada segundo critérios de Tanner e indicadores de adiposidade avaliados por adipômetro e cirtometria, respectivamente. Para as variáveis qualitativas utilizamos proporção e com respectivos intervalos de confiança de $95 \%$, teste de Rao-Scott. Devido a não normalidade dos dados, foi realizado o teste de correlação de Spearman e regressão interquantílica, para analisar a variação mediana dos indicadores de adiposidade ajustados pela idade de acordo com cada status de maturação sexual. Dada a complexidade do processo amostral, foi realizado uma correção para amostra complexa pelo comando svy do programa Stata 11.0. RESULTADOS: Foram analisados 2.412 indivíduos, sendo a maioria do sexo feminino $(52,6 \% ; n=1.408)$. Para ambos os sexos, houve correlação de moderada a fraca entre a idade e os indicadores de adiposidade. A análise revelou que: meninos que maturam fora do período normal não apresentam aumento da somatória das dobras cutâneas, como encontrado nos que maturaram no período normal; meninas que maturaram precocemente tem aumento dos indicadores de adiposidade com a idade e as que maturaram tardiamente tem redução. DISCUSSÃO: Ao final do estirão puberal ocorre a desaceleração do crescimento e a menarca, e meninas ganham peso por aumento do tecido adiposo numa escala maior do que meninos, bem como encontramos nos nossos resultados. Alterações endócrinas presentes no processo puberal podem ser responsáveis pelo ganho de peso. CONCLUSÃO: Há efeito modificador do status de maturação precoce sobre a relação entre idade e aumento dos indicadores de adiposidade, principalmente em meninas.

Palavras-chave: adiposidade, maturação sexual, obesidade

Apoio financeiro: FAPESP 


\title{
CARACTERIZAÇÃO PSICOSSOCIAIS DE ADOLESCENTES VÍTIMAS DE VIOLÊNCIA
}

\author{
Luan Salguero de Aguiar, Camen Silvia Molleis Galego Miziara
}

E-mail: luan.salguero@hotmail.com

INTRODUÇÃO: A adolescência é uma fase importante no desenvolvimento humano, na qual ocorrem transformações biológicas e psicossociais que definirão as características do indivíduo. Todavia, eventos adversos, como a violência, podem influir negativamente no desenvolvimento desses jovens para toda a sua vida. OBJETIVO: Descrever e comparar o nível de qualidade de vida e o perfil psicossocial de adolescentes vítimas de violência com aqueles não-vítimas. MÉTODO: Aplicação de 4 questionários validados em analisar nível de ansiedade, depressão, qualidade de vida e socioeconômico, além do Termo de Consentimento Livre e Esclarecido, para voluntários discentes das instituições FMABC e EPUFABC. A amostra foi dividida em: Grupo Controle (GC) - alunos que não foram vítimas de violência na adolescência; Grupo de Estudo (GE) - alunos que sofreram algum tipo de violência durante a adolescência. RESULTADOS: Os valores obtidos através de tabulação e análise de tendências demonstram os seguintes resultados: maior Grau de Depressão, Ansiedade, Dor e Limitações por Aspectos Emocionais no GE, enquanto os outros valores analisados apresentam pequenas diferenças. Além disso, obtém-se também que, no GE, $62 \%$ é classificado como Classe Econômica C ou inferior, $68,2 \%$ é do sexo feminino e $57,8 \%$ dos casos de violência era do tipo sexual, seguido por $45,8 \%$ do tipo física. DISCUSSÃO: A partir dos resultados, é possível fazer uma caracterização do GE, no qual se descreve que os valores de ansiedade, depressão, dor e as limitações por aspectos emocionais são mais evidentes que no GC, o que indica que o desenvolvimento da saúde mental do adolescente é muito prejudicado quando esse é acometido por violência, mesmo que isso não traga impacto tão significante em aspectos relacionados ao seu desenvolvimento físico. Além disso, nota-se que o público mais acometido é o do sexo feminino e socioeconomicamente afetados. CONCLUSÃO: Comprova-se que a violência é fator significante no desenvolvimento psicossocial dos adolescentes, sobretudo do sexo feminino e economicamente afetados, podendo torná-los indivíduos portadores de transtornos de humor com baixa saúde mental e qualidade de vida. Assim, é necessário promover intervenções que aumentem a segurança desses indivíduos, bem como auxiliar para restaurar ou ao menos minimizar os efeitos psicossociais estimulados pela violência.

Palavras-chave: adolescência, violência, caracterização psicossocial 


\section{NF-KB COMO BIOMARCADOR PARA NEFROPATIAS EM DIABETES MELLITUS TIPO 2}

Luisa Emanuela Biseo Henriques, Marcelo Rodrigues Bacci, Beatriz da Costa Aguiar Alves, Matheus Moreira Perez, Glaucia Raquel Luciano da Veiga, Amanda Bosio Quinzani, Matheus Gonçalves Della Nina Raffo, Fernando Luiz Afonso Fonseca

E-mail: luisa_henriques@hotmail.com

INTRODUÇÃO: A nefropatia diabética (ND) é a principal causa de doença renal e expansão da matriz mesangial. Na ausência de testes mais definitivos para diagnóstico em fase inicial dessa patologia, alguns biomarcadores têm sido pesquisados com esse intuito. O NF-kB tem sido proposto como importante nas complicações vasculares da diabetes. OBJETIVO: Os objetivos do trabalho são o estudo da expressão do NF-kB na urina de pacientes com diabetes mellitus tipo 2(DM2); e a caracterização da expressão do NF-kB em pacientes com DM2 sem ND e sua correlação com o desenvolvimento da ND. MÉTODO: Trata-se de estudo transversal onde pacientes com DM2 e doadores saudáveis com idade superior ou igual a 21 anos foram recrutados no Ambulatório de Especialidades da FMABC. Os dados demográficos foram coletados na entrevista inicial após assinatura do termo de consentimento livre e esclarecido. Amostras de sangue e urina foram coletadas e avaliadas. Foi realizada extração de mRNA e síntese de cDNA a partir do sedimento urinário para analisar a expressão dos NF-kB na urina dos participantes. Também foram avaliados a TFG, controle glicêmico, creatinina sérica, creatina urinária e albumina urinária. Foi utilizado o teste de Mann-Whitney e valor de $\mathrm{P}<0,05$ será considerado estatisticamente significativo. RESULTADOS: Foram incluídos no estudo 22 participantes, $63,6 \%$ eram do sexo feminino e $33,3 \%$ do sexo masculino. A média de idade+DP dos participantes foi de $64 \pm 10$. O valor médio de glicemia, HbGlic, creatinina urinária e proteinúria foram, respectivamente, $143 \pm 40$ $\mathrm{mg} / \mathrm{dL}, 6,5 \pm 2 \%$., 50,3 $\pm 13 \mathrm{mg} / \mathrm{dL}$ e 17,2 $\pm 30 \mathrm{mg} / \mathrm{dL}$. A média de expressão de NFKB foi de 5.80277 \pm 9.16814 . DISCUSSÃO: A doença renal no paciente diabético é um processo que ocorre lentamente ao longo de anos, visto que a maioria dos exames como albuminúria, não se correlacionam com glomeruloesclerose na fase inicial da ND. Sendo assim, é importante o estudo de novos candidatos a biomarcadores para o diagnóstico precoce, como o NF-kB. Apesar da análise da expressão do NF-kB e a e sua correlação com o desenvolvimento da ND em pacientes com DM2 não ter apresentado resultado estatisticamente significante no estudo, não diminui a importância do assunto abordado e a necessidade de novos estudos. CONCLUSÃO: Não houve correlação estatisticamente significante entre a expressão do NF-kB e os principais indicadores de perda de função renal.

Palavras-chave: diabetes, nefropatia diabética, biomarcadores, NF-kB

Apoio financeiro: PIBIC CNPq 


\section{MÉTODO ANALÍTICO ALTERNATIVO PARA QUANTIFICAÇÃO DA CAPACIDADE ANTIOXIDANTE DE AMINOÁCIDOS E AMOSTRAS SINTÉTICAS DE SORO UTILIZANDO OS COMPLEXOS DE FE(III) COM O ÁCIDO NITROSO-2-NAFTOL-3,6-DISSULFÔNICO}

Luísa Menezes de Carvalho, Maryane Woth de Souza, Fernando Luiz Affonso Fonseca, Horácio Dorigan Moya

E-mail: luisa_mcarvalho@hotmail.com

INTRODUÇÃO: Acredita-se que grande parte das patologias é devido à presença de radicais livres em excesso que diminuem a capacidade antioxidante no organismo originando o stress oxidativo. Dessa forma, é sempre útil ter disponíveis métodos alternativos que possam medir diretamente a capacidade antioxidante total (CAT) de amostras biológicas. OBJETIVO: Desenvolver método analítico espectrofotométrico simples e menos oneroso para a quantificação da CAT de amostras de soro utilizando os complexos de $\mathrm{Fe}(\mathrm{III})$ com o ácido nitroso-2-naftol-3,6-dissulfônico $\left(\mathrm{H}_{2} \mathrm{NRS}\right)$. MÉTODO: Os ensaios para a determinação da CAT foram efetuados no equipamento HPUV 8453 Diodo Array (cubetas de vidros de 1,0 cm de caminho óptico). Inicialmente investigou-se a oxidação CAT de 20 aminoácidos (aa) por íons Fe(III) em uma solução

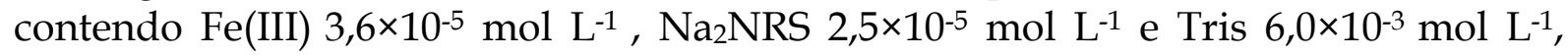
originando os complexos de Fe(NRS) $2^{4-}$, medidos na absorbância de $730 \mathrm{~nm}$. Dos $a a^{\prime} \mathrm{s}$ avaliados somente a cisteína (Cys) apresentou forte caráter redutor nas condições experimentais do presente estudo (TRIS;pH 8,0), o que pode ser atribuído à presença do grupo sulfidrila livre. Em seguida, foi obtida uma curva de calibração com a solução padrão de Cys para quantificação da CAT das amostras biológicas. Essa solução foi substituída por alíquotas de soro repetindo-se o procedimento acima descrito. Para efeito de comparação a determinação da CAT das amostras também foi feita com os reagente de Folin Cicalteau (RFC) e o complexos de Fe(III)/2,4,6-tri-(2-piridil)-1,3,5triazina (TPTZ). RESULTADOS E CONCLUSÕES: Os valores de CAT obtidos para 17 amostras com o complexo Fe(NRS) $2^{4-}$ concordam tanto com o RFC quanto com o complexo Fe(III)/TPTZ, sugerindo que o método proposto também pode ser usado para quantificar o CAT em amostras biológicas. Nas amostras analisadas não foi encontrada correlação entre os valores de $\mathrm{CAT}_{\mathrm{Cys}}$ (em ambos os métodos) com o teor de albumina ou de proteína. Compostos como ácido úrico e bilirrubina podem os ser responsáveis pelos valores de CAT encontrados.

Palavra-chave: aminoácidos, NRS, antioxidante

Apoio financeiro: PIBIC CNPq 


\title{
AÇÃO DE DIFERENTES POTÊNCIAS DO MEDICAMENTO HOMEOPÁTICO BELLADONNA EM CULTURAS DE STREPTOCOCCUS PYOGENES “IN VITRO”
}

\author{
Marcella Eiras da Rossi, Tânia Aguiar Passeti, Andrea de Andrade Ruggiero \\ E-mail: marcella.rossi@hotmail.com
}

INTRODUÇÃO: Um dos patógenos mais relevantes para o ser humano é Streptococcus pyogenes, que causa entre outros sintomas a escarlatina. Em trabalho recente, Passeti avaliou a ação de cinco medicamentos homeopáticos no crescimento "in vitro" do $S$. pyogenes, a Belladonna e o isoterápico da bactéria inibiram o crescimento "in vitro" significativamente. Em 1799, Hahnemann utilizou a Belladonna na epidemia de escarlatina na Alemanha, obtendo excelentes resultados. OBJETIVO: Propomos uma investigação na ação de diferentes potências do medicamento homeopático Belladonna sobre o crescimento do S. pyogenes "in vitro". MÉTODO: A bactéria S. pyogenes foi diluída a 0,5 da escala de McFarland e posterior $1 / 10$. O medicamento foi utilizado nas diluições de 1 a $30 \mathrm{CH}$ sequenciais e, alternadas de 36, 42, 45, 48, 54, e $60 \mathrm{CH}$. Foi adicionado $250 \mu \mathrm{L}$ de cada diluição em $3 \mathrm{~mL}$ de meio Mueller Hinton (MH) e $10 \mu \mathrm{L}$ da bactéria diluída. Essa suspensão bacteriana foi distribuída em tubos e, incubada por 48 horas em estufa a $37^{\circ} \mathrm{C}$. As amostras foram racionadas em placa de 96 poços em 100 $\mu \mathrm{L}$ por poço e, avaliadas em leitor com filtro de $620 \mathrm{~nm}$. Na dosagem de hemoglobina a bactéria S. pyogenes foi diluída na concentração 0,5 da escala de McFarland e 1/10. As diluições do medicamento utilizadas em $250 \mu \mathrm{L}$ por $3 \mathrm{~mL}$ de $\mathrm{MH}$ acrescido de $5 \%$ de hemácias de carneiro, nesse homogeneizado adicionamos $10 \mu \mathrm{L}$ da bactéria diluída, essa suspensão foi distribuída em tubos de ensaio e incubada por 48 horas em estufa a $37^{\circ} \mathrm{C}$. As amostras foram centrifugadas a $2000 \mathrm{rpm}$ por 5 minutos, e o sobrenadante distribuído em placa de 96 poços com $100 \mu \mathrm{L} /$ poço e, avaliadas em leitor com filtro verde. RESULTADOS: A Belladonna dinamizada foi capaz de inibir significativamente o crescimento do S. pyogenes, esse foi melhor observado nas altas potências. As potências com melhores resultados foram compatíveis com as sugeridas na matéria médica, principalmente 7,15 e $30 \mathrm{CH}$. O teste da dosagem da hemoglobina, demonstrou aumento significativo desta célula na bactéria incubada com altas potências da Belladonna. Devido a originalidade desse método, faz-se necessário outros testes para comprovação desses dados. CONCLUSÃO: Esses resultados sugerem que altas potências do medicamento homeopático Belladonna, reduzem o crescimento do $S$. pyogenes "in vitro" e possivelmente influenciam na produção de enzimas bacterianas.

Palavras-chaves: streptococcus pyogenes, homeopatia, Belladonna e in vitro 


\section{CRIAÇÃO DE MODELO EXPERIMENTAL DA DOENÇA DE PEYRONIE}

Marília Arrais Garcia, Giuliana Petri, David Jacques Cohen, Thérèse Rachell Theodoro, Maria Aparecida da Silva Pinhal, Sidney Glina

E-mail: marilia.arrais@hotmail.com

INTRODUÇÃO: A doença de Peyronie (DP) é caracterizada pela formação de placas fibrosas na túnica albugínea (TA) peniana, ocasionando deformidades durante a ereção. Atualmente a sua fisiopatologia é controversa, porém aparentemente o TGF- $\beta$ tem papel relevante na formação da placa. Este estudo faz parte de uma linha de pesquisa que visa reproduzir o que ocorre na TA na DP. Em estudo anterior, reproduzimos algumas destas alterações injetando sangue do próprio animal na TA. OBJETIVO: Avaliar se a injeção de plasma fresco, mais rico em TGF- $\beta$, amplia estas alterações. MÉTODO: Foram utilizados 30 ratos machos da raça Wistar separados em 3 grupos: controle 15 dias ( 5 ratos) instilação de 20ul de água destilada na TA + penectomia após 45 dias; Experimental 15 dias (5 ratos) instilação de 20 ul de plasma do próprio rato na TA + penectomia após 15 dias; Experimental 45 dias (5 ratos) instilação de 20 ul de plasma do próprio rato na TA + penectomia após 45 dias. Foram realizadas análises histológicas com coloração de HE (processo inflamatório; microvasos); As amostras foram submetidas à reação de imunohistoquímica (IHQ). A dosagem de glicosaminoglicanos (GAG) foi analisada por eletroforese em gel de agarose. RESULTADOS: Foi observado aumento significativo de TGF- $\beta$ nas amostras de animais com instilação de plasma, especialmente no grupo experimental 15 dias. As análises realizadas por IHQ demonstraram aumento significativo de MMP9 nos grupos experimentais, principalmente no de 15 dias. No entanto a expressão de HPSE, HPSE2 E MMP2 não apresentou valores significativos. A dosagem tecidual de GAG também se manteve sem alterações significativas nos 3 grupos analisados. DISCUSSÃO: Sugere-se então que altos níveis de TGF- $\beta$ estão envolvidos no início do processo inflamatório, sendo necessárias menores concentrações para sua perpetuação. Em relação à MMP9, seu aumento está relacionado ao processo de remodelamento da MEC. Embora as heparanases, MMP2 e GAG estejam envolvidos com o remodelamento da MEC, nesse modelo não foram encontradas diferenças significativas, sugerindo rápida resposta citoplasmática (turnover). CONCLUSÃO: Neste modelo experimental em ratos, foram encontradas alterações histológicas e bioquímicas, principalmente de TGF- $\beta$ e MMP9, compatíveis com o remodelamento da MEC que ocorre em doenças inflamatórias crônicas, semelhantes à DP.

Palavras-chave: doença de peyronie, matriz extracelular, MMP9, TGF- $\beta$

Apoio financeiro: PIBIC CNPq 


\section{POLIMORFISMOS DO GENE DA MATRIZ DA METALOPROTEINASE COMO FATOR DE RISCO PARA A DEGENERAÇÃO DISCAL}

Matheus Defino, Aline Amaro, Carla Peluso, Igor Luiz Argani, Bianca Bianco, Luciano Miller

E-mail: matheusdefino@gmail.com

INTRODUÇÃO: A degeneração discal (DD) envolve um aumento da sintese de moléculas que favorecem o catabolismo, assim como a matriz de metaloproteinase (MMP), o que promoverá uma degradação da estrutura do disco intervertebral. Assim, a presença de variantes genéticas no gene da metaloproteinase poderiam agir desbalanceado a síntese e degradação da matriz óssea, contibuindo com a degeneração discal. OBJETIVO: Avaliar a frequência de polimorfismos rs243865 C/T e rs2285053 $\mathrm{C} / \mathrm{T}$ do gene MMP2 em pacientes com degeneração discal e no grupo controle. MÉTODO: Estudo caso-controle com 119 pacientes portadores de degeneração discal e 109 indivíduos saudáveis como controles. A genotipagem foi realizada pelo sistema TaqMan por PCR em tempo real. A distribuição de genótipos e a frequência de alelos foram calculadas. RESULTADOS: A frequência dos genótipos para os polimorfismos estudados estava em equilíbrio de Hardy-Weinberg para os grupos caso e controle, exceto para o polimorfismo rs243865 para o grupo com DD ( $\mathrm{p}=0,028)$. Considerando o polimorfismo rs243865, houve associação positiva com a DD (alelo polimórfico T, $\mathrm{p}=<0,001, \mathrm{OR}=3,69,95 \%$ IC $-2,01-6,79)$. Em relação ao polimorfismo rs2285053, também houve associação positiva com a DD (alelo polimórfico T, p=0,01, OR=2,36, 95\% IC - 1,20-4,64). DISCUSSÃO: Dong et al (2016) estudaram o polimorfismo rs243865 e encontraram associação entre genótipo homozigoto selvagem (CC) e o aumento do risco em até 3 vezes para o aparecimento da DD, dado este que corrobora nossos resultados. Zhang et al. (2013) estudaram o polimorfismo rs2285053 e encontraram associação entre o genótipo homozigoto selvagem (CC) e o aumento do risco em até 2,5 vezes para o aparecimento da DD, sendo correlacionados também graus mais elevados de degeneração neste mesmo genótipo. CONCLUSÃO: Este é o primeiro estudo na população brasileira considerando os polimorfismos rs $243865 \mathrm{C} / \mathrm{T}$ e rs2285053 C/T do gene MMP2 em pacientes com DD, onde o alelo polimórfico de ambos os polimorfismos conferiram maior risco para o aparecimento de degeneração discal.

Palavras-Chave: degeneração discal, polimorfismos genéticos, metaloproteinase, gene MMP2

Apoio financeiro: PIBIC CNPq 


\section{ESTUDO COMPARATIVO E RANDOMIZADO DOS EFEITOS TERAPÊUTICOS DA BETAMETASONA + HIALURONIDASE TÓPICA COM APLICAÇÕES DO PRODUTO SEM E COM TRAÇÃO DO PREPÚCIO}

Matheus Prado Nascimento, Fabio Jose Nascimento, Alexandre Kiyoshi Hidaka, Marcos Tobias Machado

E-mail: max_nascimento@hotmail.com

INTRODUÇÃO: A fimose é uma doença comum na pratica diária de urologistas, pediatras e cirurgiões infantis, $10 \%$ das crianças apos os 3 anos apresentam essa patologia. É definida como a incapacidade de retração do prepúcio (pele que recobre a extremidade do pênis), impedindo assim a exteriorização da glande. $O$ tratamento pode ser clinico, utilizando-se cremes tópicos a base de corticoides ou descolamento das aderências através de manobras digitais com o uso de anestésicos locais. Pode-se ainda realizar um tratamento cirúrgico, a postectomia convencional e a postectomia com dispositivo plásticos. Entretanto, estudos recentes demonstraram que o tratamento clínico em cremes tópicos a base de corticoides pode ser uma alternativa. OBJETIVO: O objetivo desse estudo é comparar os efeitos terapêuticos da aplicação do Valerato de Betametasona 0,2\% + Hialuronidase tópico com e sem tração do prepúcio para o tratamento da fimose. Para demonstrar se há diferença na taxa de cura devido ao método de aplicação escolhido. MÉTODO: Trabalho prospectivo, randomizado e comparativo. A amostra foi de 15 pacientes portadores de fimose, com idade igual ou superior a três anos e inferior a dez anos de idade. As fimoses foram classificadas pela classificação de Kayaba. Foi usado Valerato de Betametazona 0,2\% + Hialuronidase tópico. Um grupo foi orientado a fazer a tração total do prepúcio para a aplicação do medicamento e outro grupo para não realizar a tração. RESULTADO: Dos 15 pacientes submetidos ao trabalho, apenas 4 foram curados da fimose. Desses, 3 não realizavam a tração do prepúcio, sobrando 1 que realizava. Dos 11 pacientes que não foram curados, 7 desses tiveram uma melhora na classificação da fimose, significando uma ação da droga. Dessas 7 crianças, 3 realizavam a tração e 4 não. Os pacientes não curados foram encaminhados para cirurgia. DISCUSSÃO: Com esses dados preliminares é possível notar que dos pacientes curados $75 \%$ não realizavam a tração. A taxa de cura foi baixa comparada com outros trabalhos na literatura, $26 \%$.

CONCLUSÃO: Assim, conclui-se que ambas as maneiras de aplicação da pomada levam a cura da fimose, porém não é possível estabelecer com certeza se um método é superior ao outro.

Palavras-chave: fimose, betametasona, tratamento tópico, corticoide 


\title{
QUANTIFICAÇÃO DA ATIVIDADE ANTIOXIDANTE TOTAL DE ÁGUAS DE COCO INDUSTRIALIZADAS EXPLORANDO A FORMAÇÃO DOS COMPLEXOS DE COBRE(I) COM ÁCIDO 4,4'- DICARBOXI-2,2'-BIQUINOLINA
}

\author{
Mayara Batista Dalaglio, Waila Evelyn Lima Santana; Horácio Dorigan Moya
}

E-mail: maydalaglio@hotmail.com

INTRODUÇÃO: Estudos epidemiológicos têm estabelecido relação direta entre o consumo de alimentos contendo antioxidantes (AO's) e a diminuição da ocorrência de patologias relacionadas ao "stress" oxidativo. Águas de coco industrializadas e da fruta apresentam grande quantidade de $\mathrm{AO}^{\prime}$ s, todavia não há na literatura um método mundialmente aceito para quantificação da atividade antioxidante total (AAT) dessas amostras. OBJETIVO: Determinar a AAT de águas de coco in natura e industrializadas utilizando os complexos $\mathrm{Cu}(\mathrm{I}) / 4,4^{\prime}$-dicarboxi-2,2'-biquinolina (BCA). MÉTODO: No método proposto utilizou-se a espectrofotometria com medições de absorbância em $558 \mathrm{~nm}$ (A558nm). Inicialmente curva de calibração (CC) com o solução de padrão de ácido ascórbico (AA) foi realizada adicionando os reagentes: $250 \mu \mathrm{L} \mathrm{Cu}$ (II) 1,0×10-2 $\mathrm{mol} / \mathrm{L}, 2,0 \mathrm{~mL}$ de acetato de amônio 2,0 mol/L (tampão pH 7,0) 50-350 $\mu \mathrm{L}$ de AA, 0,176 $\mathrm{mg} / \mathrm{mL}$ e $250 \mu \mathrm{L}$ de BCA 3,0×10-2 mol/L em balões volumétricos de $5 \mathrm{~mL}$. Em seguida foram realizadas $\mathrm{CC}^{\prime}$ 's com as amostras substituindo AA por alíquotas de águas de coco industrializadas $(200-800 \mu \mathrm{L})$ ou in natura $(300-1100 \mu \mathrm{L})$. Comparando a CC obtida com AA, em mg/mL, $\left(\mathrm{A}_{558 \mathrm{~nm}}=\mathrm{a}+\mathrm{b} \times \mathrm{C}_{\mathrm{AA}}\right)$ com a CC da amostra de águas de coco, também em mg/mL, (A $558 \mathrm{~nm}=\mathrm{a}+\mathrm{b} \times$ Cágua de coco $)$ foi possível quantificar a AAT de das amostras em mg AA / $\mathrm{mL}$ de água de coco. Os valores do teor total de polifenol (TTP), obtido com o reagente Folin Ciocalteu, e da AAT obtido com o método que consome o radical livre $\mathrm{ABTS}^{\bullet+}$ foram expressos em $\mathrm{mg}$ de ácido pirogálico/g água de coco e $\mu \mathrm{M}$ Trolox/g de água de coco, respectivamente. RESULTADOS E CONCLUSÕES: Nas amostras industrializadas analisadas observou-se boa concordância $\left(\mathrm{r}^{2}=0,611\right)$ entre os valores de AAT obtidos com o método proposto e com o método do ABTS, sugerindo que ambos podem ser usados para quantificar a AAT dessas amostras. Além disso, os valores obtidos da AAT com o método proposto comparados com o TTP também originaram correlação positiva $\left(\mathrm{r}^{2}=0,719\right)$, sugerindo que os polifenóis devem ser os responsáveis pela AAT.

Palavras-chave: atividade antioxidante, água de coco, cobre, 4,4'-dicarboxi-2,2'biquinolina

Apoio financeiro: PIBIC Institucional NEPAS 


\section{COMPLICAÇÕES RESPIRATÓRIAS EM RECÉM-NASCIDOS COM DIAGNÓSTICO DE ATRESIA DE ESÔFAGO}

Mayara Pereira de Carvalho, Gabriela Ay Casa Grande, Claudia Lunardi Savordelli

E-mail: mayara_2607@hotmail.com

INTRODUÇÃO: Atresia de esôfago (AE) é uma má formação congênita do esôfago, no qual este se separa em dois cotos, que podem ou não se ligar à traqueia, ou seja, o esôfago não completa a sua formação, contendo duas porções (proximal e distal). $\mathrm{O}$ tratamento da $\mathrm{AE}$ é feito através de intervenções cirúrgicas que levam a complicações respiratórias. OBJETIVO: Verificar as complicações respiratórias pós-natais dos RN com diagnóstico de AE internados na UTI neonatal do Hospital Mário Covas. MÉTODO: Foram analisados 20 prontuários com diagnóstico de $\mathrm{AE}$, no período de janeiro de 2009 a junho de 2016, com enfoque nas informações: sexo, IG, prognostico, tipos de cirurgia, uso de ventilação mecânica (VM) e complicações respiratórias. RESULTADOS: Dos 20 RN, 65\% eram do sexo masculino, com IG de 38 semanas, $85 \%$ tiveram alta e $70 \%$ fizeram correção cirúrgica primária (esofagoplastia), com mediana de 54 dias de internação. Além disso, 65\% fizeram uso de VM e as principais complicações respiratórias foram: atelectasia (35\%), pneumotórax (35\%), infiltrados e borramento da área cardíaca(30\%), pneumonia e broncopneumonia(20\%), outros(35\%). DISCUSSÃO: AE é uma má formação congênita que acomete RN, com etiologia desconhecida. $O$ tratamento cirúrgico consistirá em esofagostomia, esofagoplastia e em duas partes. Apesar de ser uma escolha benéfica, a VM traz prejuízos, deixando a capacidade ventilatória do RN deprimida, aumentando o risco das complicações secundárias, devido ao uso continuo e prolongado. Para que os RN tenham maior conforto respiratório e menores complicações no seu desenvolvimento, a fisioterapia respiratória se faz presente com objetivo de manter as vias aéreas pérvias, diminuir o desconforto e trabalho respiratório e melhorar a relação ventilação/perfusão. Logo, ela é um recurso terapêutico para prevenção de complicações respiratórias, pois atuará diretamente nestas, proporcionando um conforto ao RN que sofre com sua patologia. CONCLUSÃO: Nota-se que a intervenção da fisioterapia respiratória é de extrema importância para pacientes $\mathrm{PO}$ de $\mathrm{AE}$, pois minimiza as complicações respiratórias inerentes a patologia e visa a melhor qualidade de vida.

Palavras-chave: atresia de esôfago, fisioterapia, complicações respiratórias 


\section{AVALIAÇÃO DA INCIDÊNCIA DE MUTAÇÕES NO GENE LHß EM MULHERES COM FALÊNCIA OVARIANA PRECOCE}

Mayla Dornas, Itatiana Rodart, Bianca Bianco, Caio Parente Barbosa, Denise Maria Christofolini

E-mail: denise.christofolini@fmabc.br

INTRODUÇÃO: A insuficiência ovariana prematura (IOP) é caracterizada pela cessação da função ovariana antes dos 40 anos. Ela afeta aproximadamente 1:1000 mulheres antes dos 30, 1:250 aos 35 e 1:100 aos 40 anos de idade e tem como principais causas as alterações cromossômicas envolvendo o cromossomo X, a pré-mutação do gene $F M R 1$ e alterações imunológicas, como a presença de anticorpos adrenocorticais e anti-tireoide, além da IOP secundária a gonadectomia, radioterapia e quimioterapia. Mutações em genes que participam do desenvolvimento e maturação dos folículos ovarianos também podem ser causa de IOP. O gene $L H \beta$ codifica a subunidade beta do hormônio LH. Este hormônio promove a ovulação por estimular a síntese de esteroides nas gônadas e mutações no gene $L H \beta$ estão relacionadas à infertilidade e ao hipogonadismo. Uma variante bastante comum do gene não foi associada à presença de IOP em nossa população. OBJETIVO: Dada a importância da IOP entre as causas de infertilidade feminina, e sabendo sobre o papel funcional do gene para a maturação folicular o presente estudo teve como objetivo avaliar a ocorrência de mutações neste gene responsáveis pelo desenvolvimento de IOP na coorte de mulheres avaliadas. MÉTODO: 60 mulheres com IOP foram selecionadas para este estudo a partir do ambulatório de Insuficiência Ovariana do Instituto Ideia Fértil de Saúde Reprodutiva, preenchendo os critérios de inclusão. Foram excluídas do estudo pacientes com causas conhecidas de IOP como alterações cromossômicas e mutação do gene FMR1. A presença de mutações no gene $L H \beta$ foi analisada por sequenciamento capilar (método Sanger). Os resultados foram comparados aos bancos de dados de variantes genômicas como clinVar, dbSNP para validação. RESULTADOS: Foram identificadas 15 variantes na região que compreende o exon 1, intron 1 e exon 2. Destas, nove eram bastante frequentes e parecem ser polimórficas em nossa população. Seis delas apareceram em menos de 3\% da amostra e nunca foram descritas nos bancos de dados públicos. Desta forma, podem estar associadas com a patogênese da IOP. CONCLUSÃO: O gene $L H B$ desempenha um importante papel da fisiologia ovariana. Variantes funcionais neste gene podem estar associadas ao processo de insuficiência ovariana precoce observado nas pacientes.

Palavras chave: falência ovariana precoce; polimorfismo, gene $L H \beta$.

Apoio financeiro: PIBIC CNPq 


\title{
INVESTIGAÇÃO DA PRESENÇA DE POLIMORFISMOS GÊNICOS ENVOLVENDO A BIOSSÍNTESE DE HORMÔNIOS ESTEROIDES E SUA ASSOCIAÇÃO AO RISCO DE OCORRÊNCIA DE ENDOMETRIOSE
}

\author{
Michelle Cristina Catto, Bianca Bianco, Caio Parente Barbosa, Denise Maria Christofolini
}

E-mail: mimi_cattosz@hotmail.com

INTRODUÇÃO: A endometriose é uma doença ginecológica benigna que afeta cerca de $10 \%$ das mulheres em idade reprodutiva, caracterizada pelo crescimento de estroma e tecido glandular de origem endometrial fora da cavidade uterina. De acordo com a localização dos focos e gravidade da doença são definidos os graus I a IV de estadiamento, sendo I e II classificados como mínimo/leve e III e IV como moderado e grave. A literatura evidencia a presença de alterações gênicas em mulheres com endometriose em comparação com mulheres sem a doença e sugere origem poligênica da condição. OBJETIVO: Avaliar a frequência de 3 polimorfismos relacionados ao metabolismo de estrógenos em pacientes com endometriose e no grupo controle. MÉTODO: Foram triadas 300 mulheres inférteis com endometriose do Ambulatório de Endometriose do Instituto Ideia Fértil e 300 mulheres férteis sem endometriose do ambulatório de Planejamento Familiar da FMABC. A genotipagem foi realizada por qPCR a partir de DNA extraído de sangue periférico. RESULTADOS: A frequência dos genótipos CC/CT/TT do rs10046 localizado no gene CYP19A1 no grupo caso foi $93 / 139 / 68$ e no grupo controle 100/136/64 $(\mathrm{p}=0,81)$. A frequência dos genótipos AA/GA/GG do rs743572 localizado no gene CYP17A1 no grupo caso foi 98/136/66 e no grupo controle 110/153/37 ( $\mathrm{p}=0,0072$ ). A frequência dos genótipos TT/TC/CC do rs605059 localizado no gene HSD17B1 no grupo caso foi 73/125/83 e no grupo controle $73 / 157 / 70(p=0,1275)$. Foi observada diferença estatisticamente significante quanto à presença do polimorfismo localizado nos genes CYP17A1 e HSD17B1. Para ambos os genes a associação foi observada para os estadiamentos III a IV da doença $(p=0,0009)$ $\mathrm{e}(\mathrm{p}=0,0250)$. A investigação das causas genéticas associadas à endometriose é de total importância para a identificação dos pacientes que possuem risco aumentado de progressão da doença, infertilidade e para a identificação das pacientes que podem se beneficiar do tratamento clínico e cirúrgico. DISCUSSÃO: Os genes do presente estudo participam da produção e metabolização do hormônio estradiol, polimorfismos nestes genes podem contribuir para o desenvolvimento e progressão da endometriose. CONCLUSÃO: Em nossa população encontramos associação com a endometriose de dois polimorfismos localizados nos genes CYP17A1 e HSD17A1, reforçando o papel do estradiol no desenvolvimento e progressão da doença.

Palavras-chave: endometriose, infertilidade, polimorfismos, PCR 


\section{CONCENTRAÇÕES DE VITAMINA D EM LACTENTES SIBILANTES E CRIANÇAS ASMÁTICAS. RELAÇÃO COM A CONDIÇÃO NUTRICIONAL E GRAVIDADE DA DOENÇA}

Mirella Regina Cimino Scaff, Fabíola Isabel Suano de Souza, Roseli Oselka Saccardo Sarni, Neusa Falbo Wandalsen

E-mail: mirellacscaff@gmail.com

INTRODUÇÃO: A asma é uma doença inflamatória multifatorial caracterizada por hiperresponsividade das vias aéreas inferiores e por limitação ao fluxo aéreo. A vitamina $\mathrm{D}$ é um pró-hormônio cuja deficiência mostrou-se causa de déficits pulmonares que podem contribuir para o quadro da asma. Estudos sugerem que baixos níveis de vitamina $\mathrm{D}$ aumentam o risco do desenvolvimento da asma, que pode ser agravada quando cursa com obesidade, porém são poucos os trabalhos na literatura abordando o tema. OBJETIVO: Avaliar as concentrações de vitamina D em lactentes sibilantes e crianças asmáticas, correlacionando esses níveis com a condição nutricional, a gravidade e o controle da doença. MÉTODO: O estudo propõe analisar 60 crianças asmáticas, eutróficas e com sobrepeso, de 0 a 10 anos de idade, matriculadas no ambulatório de Alergia e Imunologia da disciplina da Clínica Pediátrica da Faculdade de Medicina do ABC. Realizou-se a seleção durante as consultas e avaliou-se o controle da asma (GINA 2017) e o estado nutricional (Escore Z-WHO). O laboratório de Análises Clínicas da FMABC realizou a análise laboratorial, e a analise estatística foi realizada no Stat. RESULTADOS: Foram incluídos 22 pacientes, 14 meninos e 8 meninas, com idade média de 6,4 anos (DP 2,23), divididos em: grupo A, eutróficos (escoreZ -2 a +1) 12 pacientes; grupo B, sobrepeso/obesidade (escoreZ $>+1) 10$ pacientes. Dez crianças apresentaram doença controlada, 6 do grupo A e 4 do grupo B; 8 apresentaram níveis normais de vitamina $\mathrm{D}(>20 \mathrm{ng} / \mathrm{mL})$ e 2 deficiência $(<20 \mathrm{ng} / \mathrm{mL}$ ). Doze não apresentaram controle da doença, 6 do grupo A e 6 do grupo B; 8 com níveis normais de vitamina D e 4 com deficiência. DISCUSSÃO: A maioria dos estudos observou relação entre o controle da asma e a condição nutricional, o que não ocorreu nesta pesquisa. Ainda se discute a associação entre deficiência de vitamina $\mathrm{D}$ e a asma de difícil controle, e este estudo não encontrou associação entre elas. Esses resultados podem ser decorrentes do pequeno número da amostra. CONCLUSÃO: $45 \%$ das crianças apresentavam asma controlada, porém não se observou relação entre o controle da doença e a condição nutricional $(p=0,691)$, assim como com os níveis de vitamina $\mathrm{D}(\mathrm{p}=0,646)$. Não houve associação entre condição nutricional e insuficiência de vitamina $\mathrm{D}(\mathrm{p}=0,646)$. Os autores propõem a continuação do estudo para a inclusão de um número maior de crianças.

Palavras-chave: asma, vitamina D, obesidade, crianças

Apoio financeiro: PIBIC CNPq 


\title{
ANÁLISE COMPARATIVA DA EXPRESSÃO DE P53 E MKI67 POR IMUNOHISTOQUÍMICA E POR QRT-PCR DE AMOSTRAS DE ADENOCARCINOMA DE PRÓSTATA GLEASON 3 ADJACENTE OU NÃO AO GLEASON 4
}

\author{
Natasha Kouvaleski Saviano Moran, Arie Carneiro, Marcos Tobias-Machado, Bianca Bianco
}

E-mail: natasha_smoran@hotmail.com

INTRODUÇÃO: O câncer de próstata $(\mathrm{CaP})$ é o segundo tumor mais frequente na população masculina. A sua forma mais "bem diferenciada" (Gleason 3) é a forma comumente encontrada; no entanto, o $\mathrm{CaP}$ de baixo risco apresenta comportamento indolente e não será o responsável pela morte do paciente. Assim é de fundamental importância a estratificação de risco e o conhecimento do comportamento biológico do $\mathrm{CaP}$ Gleason 3 para determinar quais pacientes deverão ser tratados. OBJETIVO: Avaliar pela análise imunohistoquímica a expressão dos genes p53 e do KI67 em amostras de CaP Gleason 3 (Grupo 1) adjacente ou não ao Gleason 4 (Grupo 2). MÉTODO: Foram selecionados amostras de blocos de parafina de pacientes portadores de $\mathrm{CaP}$ de baixo risco, com critério para vigilância ativa, que foram submetidos a prostatectomia radical nos serviços de Urologia da FMABC. A análise Imunohistoquímica foi realizada para o anticorpo Ki67 (clone 30-9) e p53 (clone SP35). A análise quantitativa foi realizada através do software "ImageScope". RESULTADOS: Foram incluídos 35 pacientes sendo 17 do grupo 1 (Gleason 3 adjacente ao Gleason 4) e 18 do grupo 2 (Gleason 3 puro). A expressão de p53 foi baixa nos grupos o que enfraquece os dados da análise realizada. $\mathrm{Na}$ análise de todas as áreas-alvo selecionadas, a expressão do KI67 foi significativamente maior no Grupo 1 $(\mathrm{p}=0,004)$. DISCUSSÃO: Estudos recentes mostraram que a expressão do p53 e KI67 pode estar relacionada com a biologia tumoral e prognóstico do CaP. Nossos resultados parecem confirmar a hipótese de que o CaP Gleason 3 adjacente ao 4 possui modificações moleculares que podem predispor a progressão do tumor, como o aumento da expressão de KI67 observado no grupo Gleason 3 adjacente ao Gleason 4. Em relação à expressão de p53, não observamos diferença entre os grupos. CONCLUSÃO: Nossa análise imunohistoquímica mostrou que o CaP gleason 3 adjacente ao G4 possui biologia diferente, o que pode estar relacionado com a sua progressão.

Palavras-chave: câncer de próstata, imunohistoquímica, p53, KI67

Apoio financeiro: PIBIC CNPq 


\title{
CONHECIMENTO DOS ALUNOS DA GRADUÇÃO EM FISIOTERAPIA SOBRE SUPORTE BÁSICO DE VIDA
}

\author{
Nathália Martins da Luz, Laércio da Silva Paiva, Luís Fernando Barbosa Tavares, Rodrigo \\ Daminello Raimundo
}

E-mail: nathaliamartinsdaluz@hotmail.com

INTRODUÇÃO: A parada cardíaca pode ser referida como a perda súbita da função ventricular útil, decorrente da falha do sistema elétrico cardíaco o que resulta em ritmos cardíacos anormais (arritmias). O suporte básico de vida é essencial para o sucesso da ressuscitação da vítima e ausência/diminuição de sequelas. De acordo com a literatura, $50 \%$ dos estudantes de fisioterapia terminam a graduação sem ter participado de algum treinamento sobre Suporte Básico de Vida (SBV). OBJETIVO: Avaliar o conhecimento dos alunos de graduação em Fisioterapia da Faculdade de Medicina do ABC sobre o suporte básico de vida. MÉTODO: Foi usado um questionário validado para avaliar o conhecimento dos alunos sobre o tema, constituído por 20 questões, 4 alternativas cada questão e somente 1 resposta correta. Para analisar associação entre o conhecimento prévio do Suporte Básico de Vida e o número de acertos foram utilizados o teste de Mann-Whitney. O nível de confiança adotado foi de $95 \%$. O programa estatístico utilizado foi o Stata versão 12.0. RESULTADOS: A amostra caracterizou-se por indivíduos adultos jovens com mediana de 21 anos (19-22), solteiros (92,7\%) com prevalência do sexo feminino (87\%) e sem conhecimento prévio sobre SBV $(94,4 \%)$. A mediana da porcentagem de acertos foi de $30 \%$ (25-40). Não houve diferença estatisticamente significante $(p=0,773)$ entre o número de acertos dos indivíduos que tiveram conhecimento prévio de Suporte Básico de Vida com mediana de acertos 5,5 (IC 95\%: 4,3; 9,7) e dos que não tiveram conhecimento prévio de Suporte Básico de Vida com mediana de acerto de 6,0 (IC 95\%: 6,0; 7,0). DISCUSSÃO: A partir dos dados apresentados algumas considerações podem ser feitas. A mediana de $30 \%$ apresentada no estudo é baixa quando comparada com o score mínimo de $84 \%$ determinado pela American Heart Association e ter conhecimento prévio sobre suporte básico de vida não influenciou no número de acertos. CONCLUSÃO: O conhecimento dos alunos de graduação de fisioterapia da Faculdade de Medicina do ABC sobre suporte básico de vida foi insatisfatório.

Palavras-chave: parada cardíaca, reanimação cardiopulmonar, avaliação, conhecimento 


\title{
AVALIAÇÃO FUNCIONAL E DO EQUILÍBRIO E MARCHA NO IDOSO POR MEIO DO ÍNDICE DE KATZ E DA ESCALA DE TINETTI
}

\author{
Paula Regina Galli, Laercio da Silva Paiva, Fernanda Antico Benetti
}

E-mail: prgalli@hotmail.com

INTRODUÇÃO: O envelhecimento é um processo natural, dinâmico, progressivo, irreversível que provoca diversas alterações no organismo. A capacidade de manter o equilíbrio torna-se diminuída com o envelhecimento. $\mathrm{O}$ desequilíbrio pode levar a queda, que representa um risco grande de incapacitação nos idosos, o que pode levar a diminuição da qualidade de vida. A atividade física é uma modalidade terapêutica que melhora a estabilidade postural e a mobilidade física, logo diminuindo o índice de quedas. OBJETIVO: O objetivo deste trabalho foi avaliar a marcha e equilíbrio do idoso pela escala de Tinetti e sua capacidade funcional pelo Índice de Katz. MÉTODO: Participaram deste estudo 76 idosos entre 60 e 80 anos, de ambos os sexos que não fossem portadores de patologias que interfiram no equilíbrio, marcha ou funcionalidade. Os voluntários foram divididos em dois grupos, sendo um grupo atividade física e outro grupo reabilitação e foram orientados a realizar as atividades de acordo com a Escala de Tinetti e o Índice de Katz. RESULTADOS: De acordo com o Índice de Katz, os 76 participantes foram classificados como independentes para suas funcionalidades. Através da Escala de Tinetti, podemos avaliar, por meio do equilíbrio dinâmico e estático que no grupo atividade física $86,8 \%$ dos idosos apresentam moderados riscos de quedas e 13,2\% não apresentam riscos de quedas. Já no grupo reabilitação, $100 \%$ dos idosos apresentam moderados riscos de queda. DISCUSSÃO: O desequilíbrio é visto como um dos principais fatores que podem limitar a vida do idoso. Uma das piores consequências do desequilíbrio pode ser a queda, situação que vem sendo cada vez mais frequente na população idosa. Dessa forma, torna-se necessário o desenvolvimento de medidas preventivas. O exercício físico aparece como uma alternativa através de programas para aumentar a força muscular, manter o peso corporal, sendo o mesmo eficiente para a locomoção e melhora do equilíbrio, diminuindo assim o número de quedas observadas nas pessoas mais idosas. CONCLUSÃO: Os resultados obtidos nesta pesquisa demonstram que grande parte dos idosos são independentes, mas, também estão propensos a quedas. Uma alternativa para melhorar o desequilíbrio nessa população é a pratica de atividade física, que traz inúmeros benefícios á saúde do idoso.

Palavras-chave: envelhecimento, equilíbrio postural, marcha, funcionalidade 


\section{AVALIAÇÃO DE POLIMORFISMOS DO GENE STAT4 EM MULHERES COM ENDOMETRIOSE}

Ramon Félix Martins Fernandes, Camila Martins Trevisan, Denise Maria Christofolini, Bianca Bianco, Caio Parente Barbosa

E-mail: ramonffernandes@yahoo.com.br

INTRODUÇÃO: A endometriose é uma inflamação crônica que representa uma das doenças ginecológicas benignas mais comuns. As teorias imunológicas sugerem que alterações no sistema imune poderiam impedir a capacidade de eliminar o endométrio da cavidade pélvica. Variantes do gene STAT4 estão amplamente implicados em diversas doenças inflamatórias e autoimunes. OBJETIVO: Avaliar os polimorfismos STAT4 rs7601754/A>G, rs11889341/C>T, rs7574865/G>T e rs7582694/C>G em mulheres com endometriose. MÉTODO: Estudo caso-controle que incluiu 439 mulheres: 174 inférteis com endometriose, 64 férteis com endometriose e 201 férteis sem endometriose (grupo controle). A genotipagem foi realizada por PCR em tempo real pelo sistema TaqMan. A distribuição de genótipos e a frequência de alelos e haplótipos foram calculadas. RESULTADOS: A análise individual revelou associação entre o polimorfismo rs7601754 e a endometriose mínima/leve nas mulheres férteis (alelo variante $G, p=0,03$ ). Nenhuma associação foi encontrada em relação aos polimorfismos rs11889341, rs7574865 e rs7582694 e a endometriose, tanto das mulheres férteis quanto inférteis e nos diferentes estádios da doença. Os genótipos combinados dos quatro polimorfismos identificaram o haplótipo "GCGG" que foi associado à proteção contra endometriose e infertilidade $(p=0,014)$, enquanto os haplótipos "ACGC" $(p=0,020)$, “ATTG" $(p=0,010)$ e "ACTG" $(p=0,032)$ foram associados com risco de endometriose e infertilidade. DISCUSSÃO: Zamani et al (2016) investigou os mesmos polimorfismos do gene STAT4 em 114 mulheres inférteis com endometriose de ascendência iraniana e 92 controles. Os resultados revelaram associação entre o polimorfismo rs7582694 (alelo C) e a endometriose. A frequência do genótipo GC também foi significativamente maior no grupo endometriose. A inconsistência entre os estudos pode ser resultado da diferença na composição étnica e também na seleção dos grupos de estudo. CONCLUSÃO: Os resultados sugerem que o polimorfismo STAT4 rs7601754 está envolvido na susceptibilidade a endometriose mínima/leve nas mulheres férteis e os haplótipos "ACGC", "ATTG" e "ACTG" estão associados com risco de endometriose e infertilidade, enquanto que o haplótipo "GCGG" que foi associado à proteção da endometriose e infertilidade.

Palavras-chave: endometriose, infertilidade, polimorfismo genético, gene STAT4

Apoio financeiro: PIBIC CNPq 


\title{
AVALIAÇÃO DE POLIMORFISMO DO GENE PRÓ-COLÁGENO TIPO I ALFA(A) 2 (COL1A2) COMO FATOR DE RISCO RELACIONADO AO DESENVOLVIMENTO DE PROLAPSO GENITAL
}

\author{
Raphael Federicci Haddad, Ricardo Peres do Souto, Emerson de Oliveira
}

E-mail: raphael_haddad@outlook.com

INTRODUÇÃO: O prolapso genital é uma patologia multifatorial que vem adquirindo maior relevância no cenário de envelhecimento populacional brasileiro. $\mathrm{O}$ mecanismo principal dessa disfunção do assoalho pélvico é o enfraquecimento das estruturas que sustentam os órgãos pélvicos, as quais são formadas, entre outros componentes, pelo tecido conjuntivo. Evidências recentes sugerem a existência de um componente genético como uma das possíveis etiologias dessa afecção. Nesse contexto, a estrutura proteica principal do tecido conjuntivo é o colágeno do tipo I, codificadas pelos genes COL1A1 e COL1A2. Essa proteína é fisiologicamente importante para promover suporte as estruturas do assoalho pélvico. OBJETIVO: Avaliar o polimorfismo rs42524 do gene da pró-colágeno tipo I alfa(a) 2 (COL1A2) como fator de risco relacionado ao desenvolvimento de prolapso genital em mulheres brasileiras. MÉTODO: Após avaliação do prolapso genital por estadiamento POP-Q (International Continence Society) foram incluídas 107 mulheres com estádios III e IV (grupo caso) e 209 mulheres com estádio 0 e I (grupo controle). Demais dados clínicos foram obtidos por anamnese, sendo também coletado o sangue das voluntárias para a extração de DNA genômico. A região promotora do gene COL1A2 contendo o polimorfismo rs42524 foi amplificada usando primers descritos na literatura e a discriminação entre as variantes G e C foi realizada por digestão dos produtos de PCR pela enzima MspA1I seguida de análise por eletroforese em gel de agarose. RESULTADOS: Foram analisadas 252 mulheres, tendo sido verificado que $144(57,1 \%)$ têm genótipo G/G, 61 (24,2\%) têm genótipo G/C e 12 (5,2\%) têm genóotipo C/C. Em 22 (8,7\%) casos, não foi possível determinar o genótipo por problemas na amplificação ou na digestão. Além disso, 13 $(5,2 \%)$ casos que foram excluídos do estudo por não atenderem aos critérios de inclusão. DISCUSSÃO: O estudo ainda está em desenvolvimento, não sendo possível analisar se existe associação desse polimorfismo com o prolapso genital. Todavia, já foi possível averiguar que os resultados até o presente momento mostram uma frequência dos genótipos semelhantes à encontrada em outros estudos. CONCLUSÃO: Como o estudo ainda se encontra em andamento, não foi possível concluir se há diferença na distribuição dos polimorfismos de COL1A2 entre as pacientes com e sem prolapso genital.

Palavras-chave: prolapso de órgãos pélvicos, polimorfismo de nucleotídeo único, colágeno

Apoio financeiro: PIBIC CNPq, FAPESP, NEPAS 


\section{AVALIAÇÃO CLÍNICO-LABORATORIAL DE FAMILIARES DO SEXO FEMININO DE PACIENTES COM DOENÇA GRANULOMATOSA CRÔNICA}

Raquel Lie Okoshi, Anete Sevciovic Grumach

E-mail: lie_okoshi@hotmail.com

INTRODUÇÃO: A Doença Granulomatosa Crônica (DGC) é uma imunodeficiência primária rara, causada pela atividade anormal do complexo enzimático nicotinamida adenina dinucleotídeo fosfato oxidase. Esta deficiência resulta na dificuldade de gerar ânions superóxidos e destruir microorganismos catalase positivos como Staphylococcus aureus, Klebsiella sp, Pseudomonas, entre outros. Há duas formas de herança: autossômica recessiva e ligada ao cromossomo X. Esta última representa a forma mais comum. A DGC manifesta-se por infecções de repetição supurativas predominantemente em pele e pulmões. Portadoras de DGC ligada ao X podem ser assintomáticas ou apresentar manifestações clínicas como Lúpus Eritematoso Discóide, aftas ou furúnculos. O diagnóstico de DGC pode ser realizado através do teste do nitroblue tetrazolium (NBT) ou o ensaio de dihidrorodamina (DHR). Estes ensaios podem detectar a doença e o estado de portador. O tratamento é feito com o uso profilático de Sulfametoxazol/Trimetoprim ou doxiciclina e com Itraconazol. OBJETIVO: Avaliar as características clínico-laboratoriais das portadoras de DGC. MÉTODO: Selecionou-se 15 centros de referência no atendimento de imunodeficiências primárias para identificar as portadoras de DGC confirmadas através do ensaio de DHR e/ou NBT. Foi realizado um estudo retrospectivo e descritivo por meio de dados coletados através de questionário elaborado. O estudo foi aprovado pelo Comitê de Ética. RESULTADO: Até o momento foram analisadas 5 portadoras de DGC. As seguintes características foram observadas: lúpus discoide (1), furunculose de repetição (1), afta (2), doença inflamatória intestinal (1). A coleta de dados ainda está em andamento. DISCUSSÃO: O estudo, até o momento, mostrou que as pacientes apresentaram manifestações clínicas como furunculose e doença inflamatória intestinal. Pacientes com o exame de DHR mais comprometido apresentaram sintomatologia mais exuberante, porém mais tardia que os pacientes com DGC. CONCLUSÃO: Embora somente a DGC ligada ao X seja classificada como imunodeficiência primária, portadoras da doença também apresentam manifestações relevantes, necessitando de abordagem terapêutica específica à semelhança dos pacientes com a deficiência total.

Palavras-chave: imunodeficiência, doença granulomatosa crônica, portador, doença inflamatória intestinal

Apoio financeiro: PIBIC Institucional FMABC 


\title{
ASSOCIAÇÃO DE SEXTING COM DEPRESSÃO, EMPATIA E IMPULSO SEXUAL EM ESTUDANTES DE MEDICINA
}

\author{
Renata de Godoy Pereira, Danilo Antonio Baltieri
}

E-mail: dbaltieri@uol.com.br

INTRODUÇÃO: Sexting é a prática de envio ou recebimento de imagens ou textos com conteúdo sexual explícito ou sugestivo através de celulares ou meios de comunicação móveis. Esse ato pode acarretar problemas sociais e legais. O projeto surgiu da necessidade de existir um estudo brasileiro que avalie aspectos psicossociais daqueles que praticam sexting, mas também da finalidade de investigar características desta população para trabalhar a prevenção, intervenção e realização de novas leis. OBJETIVO: Avaliar empatia, impulso sexual e depressão em quem pratica sexting. Os objetivos específicos são: Relacionar sintomas depressivos com receber imagens/texto com conteúdo sexual, relacionar empatia com envio de imagens contendo imagens/texto sexuais, relacionar impulso sexual com sexting, realizar tipologia de praticantes de sexting, baseada nas características psicométricas a serem investigadas. MÉTODO: Aplicação de questionários e escalas validadas em estudantes de medicina. O projeto de pesquisa é descritivo, seccional, retrospectivo, baseado na coleta de dados com questionários e inventários padronizados. RESULTADOS: O projeto está em fase de aplicação de questionários, a análise estatística final com todas as propostas acima será realizada posteriormente ao término projeto. DISCUSSÃO: Mesmo com pequeno tamanho de amostra neste momento, ficamos intrigados com o fato daqueles participantes que assumiram a prática de sexting terem uma frequência menor de uso de álcool na vida relação a aqueles que negaram esta prática. É possível que a maior impulsividade sexual, o baixo desconforto pessoal com consequências sociais também possa estar acompanhado com uma precocidade à exposição a riscos, o que apenas poderá ser cogitado ao final da coleta desta amostra. Os principais achados sociodemográficos da população estudada são: idade média da amostra é de 21 anos, $65 \%$ já fizeram uso de bebidas alcoólicas na vida, e a maioria é de orientação heterossexual. CONCLUSÃO: As análises estatísticas estão sendo realizadas e o projeto está em fase final de coleta de dados.

Palavras-chave: sexting, nudes, pornografia

Apoio financeiro: PIBIC CNPq 


\title{
A RELAÇÃO ENTRE O INÍCIO DA COLONIZAÇÃO E A FRAGMENTAÇÃO DA FLORESTA: UM DESAFIO PARA MALÁRIA DE FRONTEIRA NOS ASSENTAMENTOS RURAIS DA AMAZÔNIA
}

\author{
Roberto Cardoso ILacqua, Gabriel Zorello Laporta \\ E-mail: rcilacqua@gmail.com / roberto.ilacqua@fmabc.br
}

INTRODUÇÃO: A malária é ainda um problema de saúde pública nos assentamentos rurais da Amazônia Brasileira. O modelo atual para a previsão da emergência de malária é o da malária de fronteira, que é a relação temporal entre o início da colonização de uma área e a maior incidência nos casos de malária. Essa taxa de incidência diminui e se estabiliza em baixos níveis após dez anos. O problema é que assentamentos antigos apresentam alto índice parasitário. A nossa hipótese é que 50\% das localidades em assentamentos rurais com alto risco de malária (IPA > 50) são áreas jovens com $\leq 10$ anos do início da sua colonização. OBJETIVO: Testar o modelo de malária de fronteira atual, estimar o tempo de colonização e a cobertura florestal em localidades em assentamentos rurais da floresta amazônica com altos índices de casos de malária, e relacionar a série temporal da malária com o tempo de colonização e cobertura florestal. MÉTODO: Localidades com altos índices parasitários (IPA > 50), 2015 ou 2016, foram selecionadas em áreas de assentamentos rurais de 04 Estados: Acre, Amazonas, Pará e Rondônia. Regredimos temporalmente cada paisagem desde 1975. O resultado esperado era que $50 \%$ das paisagens seriam jovens (com idade $\leq 10$ anos). Foi utilizado o software de geoprocessamento QGis, e o banco de dados de imagens de satélite Landsat ${ }^{T M}$. RESULTADOS: A frequência relativa de paisagens com $\leq 10$ anos foi de $16,67 \%$, e 86,33\% possuem > 10 anos. O modelo de malária de fronteira atual acertou apenas 16,67\% das paisagens estudadas. DISCUSSÃO: O modelo de malária de fronteira atual foi desafiado a estimar cerca de $50 \%$ das paisagens com início da colonização especificado $\leq 10$ anos. No entanto, o modelo previu corretamente $16 \%$ das paisagens com os critérios especificados: alto índice de malária e $\leq 10$ anos de idade. O nosso modelo foi mais sensível ao efeito de borda de floresta e não ao tempo de colonização. CONCLUSÃO: O modelo de malária de fronteira atual trata-se de um modelo com baixo nível de previsibilidade, pois não permite a inferência. Pois nos parece que é o efeito de borda de floresta o mecanismo subjacente à emergência de malária na fronteira amazônica.

Palavras Chaves: malária, assentamentos rurais, áreas de fronteira, floresta Apoio financeiro: PIBIC CNPq 


\title{
CARACTERIZAÇÃO DO PERFIL EPIDEMIOLÓGICO E CLÍNICO DE PACIENTES SUBMETIDOS A HEMODIÁLISE
}

\author{
Rodrigo Scabora, Bruno Oliveira Cardelino, João Antônio Correa
}

E-mail: rodrigo9393@gmail.com

INTRODUÇÃO: A hemodiálise é um tratamento que auxilia na sobrevida de pacientes com insuficiência renal por meio de uma circulação extracorpórea estabelecida para realizar filtração do sangue, e por isso há necessidade de um acesso vascular adequado. Dentre eles podem-se ressaltar as fístulas arteriovenosas (FAV) e os cateteres venosos $(\mathrm{CV})$. As indicações para tipos de acesso vascular relacionam-se com características e restrições de uso de cada paciente. OBJETIVO: Descrever o perfil epidemiológico e clínico de pacientes submetidos a hemodiálise no Hospital Anchieta (HA) e no Hospital Estadual Mario Covas (HEMC). MÉTODO: Foi realizada coleta de dados de pacientes submetidos a hemodiálise no HA e HEMC. Os voluntários foram informados sobre o estudo e, após concordarem, assinaram um termo de consentimento livre e esclarecido. Os pacientes foram identificados através de informações como sexo, idade, tempo de tratamento, tipos de acessos já utilizados, doença de base. Os dados do estudo foram obtidos a partir de uma ficha cadastral, prontuários, exames complementares ou dados pessoais, todos coletados pelo pesquisador. Foram incluídos pacientes com insuficiência renal crônica submetidos a hemodiálise de ambos os sexos sem restrição de idade. Os pacientes não aptos à realização de FAV ou CV foram excluídos. RESULTADO: Entre os 252 pacientes que compõem a amostra, predomina-se o sexo masculino $(60,7 \%)$ e a etnia parda $(42 \%)$. O uso atual de FAV é majoritário $(76,6 \%)$ em relação ao uso de CV. Ademais, 56\% dos pacientes apresentam complicação relacionada à hemodiálise. Entre os que desenvolveram complicação, 77,3\% faz uso de FAV, e 22,7\%, de CV, sendo $\mathrm{p}=0,762$. DISCUSSÃO: Os resultados permitem compreender características tanto da população atendida nesses dois hospitais quanto do serviço oferecido, permitindo compará-lo ao que é preconizado na literatura científica sobre o tema. CONCLUSÃO: Sob perspectiva de acesso vascular, conclui-se que a hemodiálise realizada no HA e HEMC está de acordo com o preconizado pela literatura europeia sobre o assunto, a qual prioriza o uso de $\mathrm{FAV}$ em detrimento ao de $\mathrm{CV}$, pelo menor risco de complicações.

Palavras-chave: acesso vascular, hemodiálise, fístula arteriovenosa

Apoio financeiro: PIBIC Institucional Ideia Fértil 


\title{
CORRELAÇÃO DAS VARIANTES DO GENE FOXL2 E RESULTADOS DE REPRODUÇÃO ASSISTIDA EM MULHERES INFÉRTEIS
}

\author{
Sâmara Chebli Baptista, Carla Peluso, Denise Maria Christofolini, Caio Parente Barbosa, \\ Bianca Bianco
}

E-mail: samarachebli@hotmail.com

INTRODUÇÃO: O gene FOXL2 desempenha papel importante na formação e ativação do folículo e na diferenciação das células da granulosa. Além disso, sua inativação nas células germinativas inibe completamente o recrutamento de folículos primordiais. Pequenas variações nesse gene poderiam determinar a variabilidade do pool folicular e assim influenciar na variabilidade de resposta a hiperestimulação ovariana controlada $(\mathrm{COH})$ e nos resultados de reprodução assistida. OBJETIVO: Correlacionar os polimorfismos rs7641989, rs13064874, rs11924939 e rs10804661 do gene FOXL2 com os resultados de $\mathrm{COH}$, número de folículos, maturidade oocitária, embriões produzidos, taxa de gestação e dosagem sérica de AMH, FSH e estradiol em mulheres inférteis submetidas à tratamento de reprodução assistida. MÉTODO: Estudo transversal com 187 mulheres inférteis $(32,5 \pm 3,4$ anos) submetidas a tratamento de reprodução assistida. As dosagens de FSH e estradiol foram realizadas por imunoensaio e de AMH por elisa (kit AMH Gen II). A genotipagem foi realizada pelo método TaqMan por PCR em tempo real. RESULTADOS: Em relação à resposta a $\mathrm{COH}, 27,8 \%$ apresentaram má resposta, 59,9\% boa resposta, $8 \%$ hiper-resposta e $4,3 \%$ síndrome do hiperestímulo ovariano. A média foi AMH $4,3 \pm 2,8 \mathrm{ng} / \mathrm{mL}, \mathrm{FSH}$ $6,4 \pm 2,1 \mathrm{mUI}$ e estradiol $45,1 \pm 12,8 \mathrm{pg} / \mathrm{mL}$. A análise individual revelou que as mulheres com o genótipo polimórfico TT do polimorfismo rs11924939 apresentaram maior número de folículos $(\mathrm{p}=0,026)$, folículos maduros $(\mathrm{p}=0,035)$ e embriões produzidos $(\mathrm{p}=0,019)$ em relação aos demais genótipos. Considerando os polimorfismos rs7641989, rs13064974 e rs10804661 não houve diferença para nenhuma das variáveis estudadas. DISCUSSÃO: Tem sido especulado que o gene FOXL2 regula as vias de sinalização relacionadas ao fator de transformação do crescimento (TGF) envolvidas na função ovariana e, portanto, poderia desempenhar um papel no recrutamento e perda do folículo primordial. Polimorfismos nesse gene têm sido associados à falência ovariana precoce em diversas populações. CONCLUSÃO: Este é o primeiro estudo a associar os polimorfismos do gene FOXL2 com a resposta a $\mathrm{COH}$ em tratamentos de reprodução assistida. No presente estudo as mulheres com o genótipo polimórfico TT do polimorfismo rs11924939 produziram duas vezes mais folículos maduros e embriões, sugerindo que este pode ser um biomarcardor para os resultados de reprodução assistida.

Palavras-chave: gene FOXL2, hiperestimulação ovariana controlada, infertilidade feminina, polimorfismos genéticos

Apoio financeiro: PIBIC CNPq 


\section{ANÁLISE DO PERFIL E DA QUALIDADE DE VIDA DE PACIENTES COM INSUFICIEENCIA RENAL CRÔNICA SUBMETIDOS Á HEMODIÁLISE}

Sandy Costa, Laércio da Silva Paiva, José Carlos Molero Junior, Fernanda Antico Benetti

E-mail: san.dy_@hotmail.com

INTRODUÇÃO: A Insuficiência Renal é caracterizada quando os rins perdem a capacidade de efetuar funções básicas, e o tratamento normalmente é iniciado nas fases mais avançadas, havendo necessidade de tratamento dialítico. A qualidade de vida de pacientes com Insuficiência Renal Crônica dependentes de hemodiálise é afetada, pois eles apresentam limitações no seu cotidiano e vivenciam mudanças biopsicossociais. OBJETIVO: Analisar o perfil e o impacto na qualidade de vida de pacientes submetidos à hemodiálise. MÉTODO: Trata-se de um estudo transversal com 55 pacientes portadores de Insuficiência Renal Crônica em tratamento hemodialítico que foram avaliados através da aplicação de questionário Sociodemográfico e do Questionário de Qualidade de Vida SF-36. Foi realizada a análise descritiva dos dados e o software estatístico utilizado foi o Stata versão 11.0. RESULTADOS: A média de idade foi de 53,21 anos, sendo 58,18\% do sexo masculino. As etiologias com maior distribuição foram Nefroesclerose Hipertensiva, Nefropatia Diabética e Glomerulonefrite Crônica. Em relação à escolaridade, houve predomínio de Segundo Grau Completo. Em relação à renda salarial, houve predomínio da Classe Social E. Com relação à atividade atual, $38,18 \%$ dos pacientes são aposentados. A média do Índice de Massa Corporal foi de $25,67 \mathrm{~kg} / \mathrm{m}^{2}$. O tempo de hemodiálise obteve valores mínimo e máximo de 3 a 228 meses, respectivamente. Com relação aos resultados do SF-36, o domínio Aspectos Físicos teve a pior média, e o domínio Saúde Mental obteve o maior valor. DISCUSSÃO: O afastamento do trabalho favorece as repercussões emocionais e a deterioração de aspectos físicos. A média do Índice de Massa Corporal representa sobrepeso, e dessa forma, torna-se importante ter bom estado nutricional, pois a Diabetes Mellitus e Hipertensão Arterial Sistêmica foram as doenças que mais induziram Insuficiência Renal Crônica. CONCLUSÃO: Os pacientes submetidos a hemodiálise apresentam queda na qualidade de vida e torna-se necessário que os profissionais de saúde implementem programas preventivos e/ou curativos.

Palavras-chave: hemodiálise, insuficiência renal crônica, qualidade de vida, perfil sociodemográfico 


\section{TRATAMENTO DE PERSISTÊNCIA DO CANAL ARTERIAL EM PREMATUROS MUITO BAIXO PESO COM IBUPROFENO VIA ORAL}

Sofia Waligora de Carvalho Lages, Marina de Souza Campana, Milene Saori Kassai, Milene Carvalho Carrilho, Paula Venturini Nireki, Jose Kleber Kobol Machado

E-mail: sofia.wcl@gmail.com

INTRODUÇÃO: O fechamento do canal arterial ocorre entre os recém-nascidos a termo por volta do $6^{\circ}$ dia de vida, enquanto que no prematuro, a persistência do canal arterial (PCA) é de 58\%. A PCA tem efeitos significantes na função miocárdica e no fluxo sanguíneo pulmonar, e pode levar à hipoperfusão sistêmica com diminuição do fluxo sanguíneo no cérebro imaturo. OBJETIVO: Avaliar a eficácia do uso de ibuprofeno via oral no fechamento do Canal Arterial em RNPT entre 3 a 4 e entre 6 a 7 dias de vida pós-natal e avaliar a prevalência de PCA nos prematuros. MÉTODO: Estudo de coorte prospectivo randomizado realizado na UTI neonatal do HMU de SBC, de 07/2015 a 08/2016, no qual foram analisados dois grupos, cada um constituído por 10 recémnascidos pré-termo com canal arterial persistente diagnosticados através de ecocardiodoppler. Analisamos o nome da puérpera, data de nascimento, gênero, idade gestacional, cronológica e corrigida; ultrassom transfontanela, ecocardiograma e exames laboratoriais pré e pós-medicação; distúrbios do RN e medicações associadas. Participaram os RNPT com $\leq 1500 \mathrm{~g}$ e evidência ecográfica de PCA. RESULTADO: Temos até o momento 11 pacientes com exclusão de 3. 50\% iniciaram uso de ibuprofeno até 3 dias de vida, e o restante até 7 dias de vida. Através do Ecocardiograma, encontramos PCA com diâmetro de 1,2-4,3mm, e $62 \%$ sem repercussão hemodinâmica, porém, $75 \%$ apresentavam repercussão clínica. Como desfecho: em 88\% dos RN houve fechamento do canal arterial após três doses de ibuprofeno e apenas 1 foi encaminhado para correção cirúrgica. DISCUSSÃO: Ohlsson et al, em revisão sistemática de 33 artigos (2190 recém nascidos) também descreve que o ibuprofeno é adequado para o fechamento do canal arterial e causa menos efeitos colaterais renais que outras drogas. Recentemente, Erdeve et al.6 conduziram um ensaio clínico controlado e randomizado de ibuprofeno via oral e descobriram uma elevada taxa de fechamento inicial com ibuprofeno via oral. CONCLUSÃO: A PCA apresenta uma incidência elevada em recém-nascidos prematuros e relaciona-se com fatores fisiológicos próprios da prematuridade. $\mathrm{O}$ ibuprofeno via oral tem boa eficácia para o fechamento de canal arterial em RNPT, tanto precocemente quanto um pouco mais tardio.

Palavras-chave: RNPT, PCA, ibuprofeno via oral

Apoio financeiro: PIBIC Institucional NEPAS 


\section{ABORDAGEM FARMACOLÓGICA DO ANGIOEDEMA HEREDITÁRIO COM INIBIDOR DE C1 NORMAL (AEHNLC1INH)}

Stéphanie Kim Azevedo de Almeida, Anete Sevciovic Grumach

E-mail: stephanie_kaa@hotmail.com

INTRODUÇÃO: O Angioedema Hereditário com Inibidor C1 Normal (C1INH) foi descrito pela primeira vez em 2000. Afeta ambos os sexos, com maior prevalência em mulheres, devido à influência hormonal. Os sintomas têm sido associados ao aumento da bradicinina e parte dos pacientes apresentam mutação do fator 12. Embora o conhecimento sobre o mecanismo envolvido seja limitado, a terapia para AEH com deficiência de C1INH foi proposta com base na sintomatologia clínica e conhecimento adquirido no AEH com déficit de C1-INH. OBJETIVO: Avaliar a resposta à terapia de pacientes sintomáticos com AEHnlC1INH propondo uma abordagem com base no mecanismo fisiopatológico reconhecido. MÉTODO: Foram incluídos pacientes com sintomas sugestivos de AEH, história familiar e C1-INH normal. As amostras de DNA foram avaliadas quanto à presença de mutações no exón 9 do gene F12. O protocolo foi aprovado pelo comitê de ética. RESULTADOS: 14 famílias (8 com mutação do fator 12) foram incluídas, com um total de 38 pacientes (33F: 5M) (idade média 34,5 anos, 9 a 69 anos). Os sintomas iniciais apareceram aos 18,5 anos (mediana) e 23/ 29 entre 1030 anos de idade. Três famílias relataram hematomas como sintomas prodrômicos. $\mathrm{O}$ edema afetou principalmente o seguinte: abdômen 27/29; face 19/29; Extremidades 12/29; Vias aéreas superiores 13/29. A terapia profilática foi: exclusão contraceptiva combinada 8/24; Ácido tranexâmico (dose média de 500-750 mg/dia) 20/29; Progestinas 15/24; Danazol 9/24; Oxandrolona 3/24. Os ataques foram tratados com doses mais elevadas de ácido tranexâmico em 9/29 pacientes; Icatibant 8/29 e inibidor de C1 derivado de plasma em 4/29. CONCLUSÃO: Embora o reconhecimento da fisiopatologia no AEHnlC1INH seja restrito, enfrentamos a necessidade de terapia nesses pacientes. Aproximadamente $2 / 3$ dos pacientes apresentam alto risco de obstrução das vias aéreas superiores. Propomos uma abordagem gradual para esses pacientes: exclusão contraceptiva combinada; baixas doses de ácido tranexâmico; progestágenos e andrógenos como profilaxia. A dosagem elevada de ácido tranexâmico foi eficaz para sintomas leves durante os ataques, mas o Icatibant e o inibidor de C1 derivado do plasma foram usados preferencialmente.

Palavras-chave: angioedema hereditário tipo III, angioedema sem urticária, inibidor de C1 esterase terapêutica 


\section{AÇÃO DE MEDICAMENTOS HOMEOPÁTICOS SOBRE O CRESCIMENTO “IN VITRO” DO SACCHAROMYCES CEREVISIAE. INFLUÊNCIA DOS MEDICAMENTOS SOBRE A ATIVIDADE FERMENTATIVA DO FUNGO}

Vinícius Crescêncio Queiroz, Leandro Ribeiro Bissoli, Rosimeire Navickas Constantino da Silva, Roberto Lopes de Almeida, Fernando Luiz Affonso da Fonseca, Tânia Aguiar Passeti

E-mail: viniciuscresq@gmail.com

INTRODUÇÃO: A homeopatia tem por finalidade fortalecer o organismo, esses podem atuar em organismo uni ou pluricelulares. O fungo Saccharomyces cerevises (S. cerevisiae) é utilizado na indústria alimentícia em processos fermentativos. OBJETIVO: Estudar a ação dos medicamentos homeopáticos Arnica Montanna, no sódio do fungo S. cerevisiae e Atropa belladonna sobre o seu crescimento "in vitro", e influências desses medicamentos nas características fermentativas do fungo sobre a matéria prima bruta da cerveja (mosto). MÉTODO: $250 \mu \mathrm{L}$ de cada medicamento feitos em álcool $30 \%$, foram colocados em tubos com $5 \mathrm{~mL}$ de ágar Saboraud (AS) ou mosto e $20 \mu \mathrm{L}$ de fungo diluído a 0,5 da escala de Macfarland e posteriormente $1 / 100$. O crescimento fúngico foi avaliado por espectofotômetria a $600 \mathrm{~nm}$ ou contagem em câmara de Newbauer. Avaliamos a produção de álcool na fermentação pelo índice BRIX, durante 7 dias de fermentação. Após a incubação do fungo com os medicamentos, $1 \times 10^{7}$ fungos/mL foram colocados em $20 \mathrm{~mL}$ de novo mosto. Esse foi incubado a temperatura ambiente por 7 dias. Avaliamos novamente o crescimento do fungo e a formação de álcool. RESULTADOS e DISCUSSÃO: Os resultados do crescimento fúngico "in vitro" em meio AS revelaram que a Arnica 30cH estimulou significativamente o crescimento fúngico, enquanto que no sódio 6 e 30cH produziram uma diminuição do crescimento significante em relação aos fungos incubados com álcool 30\%. Quanto a produção de álcool em meio SA, observamos que a Arnica $30 \mathrm{cH}$ consumiu uma quantidade significativa menor de açúcar, enquanto que no sódio $30 \mathrm{cH}$ consumiu uma quantidade maior de açúcar em relação ao álcool $30 \%$. Os resultados do crescimento fúngico com o mosto foi similar com meio SA, onde a Arnica 6 e30 $\mathrm{cH}$ e a Belladonna 30 $\mathrm{cH}$ apresentaram um aumento significativo no crescimento fúngico, enquanto que no sódio 6 e 30cH diminuíram significativamente o crescimento "in vitro". Após, esses fungos foram colocados em $20 \mathrm{~mL}$ de mosto na concentração de $1 \times 10^{7}$ fungos/mL, e esse deixado incubando por 7 dias. Os resultados demonstraram que as diferenças no crescimento fúngico desaparecem, assim como o consumo de açúcar torna-se homogenia. Demonstrando que a ação dos medicamentos homeopáticos parece existir apenas quando ele está em contato com a célula, não perdurando após a troca do meio. A análise do odor do mosto após a fermentação demonstrou nítida diferença entre os tratamentos, o mosto com fungo incubado com Belladonna apresentou um odor mais alcoólico, enquanto o mosto com fungos incubados no sódio apresentaram um odor mais floral. CONCLUSÃO: O tratamento do fungo Saccharomyces cerevisiae pelos medicamentos homeopáticos Arnica, Belladonna e nosodio do S. cerevisiae produziu uma modulação significativa no crescimento fúngico e na geração do álcool na fermentação.

Palavras-chave: homeopatia, Sacharomyces cerevisiae "in vitro", fermentação 